Research Paper

\title{
Expression profile and prognostic values of Chromobox family members in human glioblastoma
}

\author{
Juanni $\mathrm{Li}^{1,2,}{ }^{*}$, Zhijie $\mathrm{Xu}^{1,{ }^{*}}$, Lei Zhou ${ }^{3}$, Kuan $\mathrm{Hu}^{4}$ \\ ${ }^{1}$ Department of Pathology, Xiangya Hospital, Central South University, Changsha 410008, Hunan, China \\ ${ }^{2}$ National Clinical Research Center for Geriatric Disorders, Xiangya Hospital, Central South University, Changsha \\ 410008, Hunan, China \\ ${ }^{3}$ Department of Anesthesiology, Third Xiangya Hospital of Central South University, Changsha 410008, Hunan, China \\ ${ }^{4}$ Department of Hepatobiliary Surgery, Xiangya Hospital, Central South University, Changsha 410008, Hunan, China \\ *Equal contribution
}

Correspondence to: Kuan Hu; email: kuan.hu@csu.edu.cn

Keywords: Chromobox (CBX), GBM, expression profiles, prognosis, immune infiltration

Received: November 1, $2021 \quad$ Accepted: January 28, $2022 \quad$ Published: February 24, 2022

Copyright: (C) $2022 \mathrm{Li}$ et al. This is an open access article distributed under the terms of the Creative Commons Attribution License (CC BY 3.0), which permits unrestricted use, distribution, and reproduction in any medium, provided the original author and source are credited.

\section{ABSTRACT}

Glioblastoma (GBM) is the most common and deadly malignant primary brain tumor. Chromobox (CBX) family proteins are essential components of the epigenetic regulatory complex and are involved in the occurrence and development of various cancers. However, the roles of CBX members in GBM is little known. In this analysis, we synthesized several mainstream bioinformatics databases to comprehensively explore the expression profiles, prognostic implications, genetic alterations, immune infiltration, and potential biological functions of the CBXs in GBM, and cell experiments were also conducted to investigate the role of CBX8 in GBM. We found that the elevated mRNA expression of $C B X 2 / 3 / 5 / 8$ and reduced mRNA expression of $C B X 6 / 7$ were found in GBM. The protein levels of CBX2/3/5/8 were elevated in GBM tissues, whereas the protein levels of CBX6/7 showed no significant difference. The upregulated expression of $\mathrm{CBX} 2 / 3 / 8$ was found to be both correlated with the tumor grade and recurrent status. The overexpression of $\mathrm{CBX3/8}$ and underexpression of CBX6 mRNA were associated with the poor prognosis. These findings suggested that $\mathrm{CBX} 3$ and $\mathrm{CBX8}$ might be useful diagnostic and prognostic biomarkers in GBM. Further cell experiment results supported that CBX8 promoted the proliferation of glioma cells. Moreover, a high genetic alteration rate of CBXs (37\%) was found in GBM and to varying degrees. The expression of CBXs was significantly related to the immune cells infiltration. CBX7 methylation level was significantly increased in GBM tissues. Our results may provide novel ideas to find potential prognostic markers and new therapeutic targets among CBX family members in glioblastoma.

\section{INTRODUCTION}

Glioblastoma (GBM) is a deadly malignant primary brain tumor, constituting $54.9 \%$ of all gliomas [1,2]. Even after various treatments including surgery, radiotherapy, and chemotherapy, the prognosis of patients with GBM is poor $[3,4]$. In the past two decades, no significant change has been made in tumors progress and overall outcomes [5]. Thus, the identification of novel biomarkers for enhancing prognosis and individualized treatment effectively is of great significance.
So far, eight CBX family members (CBX1-8) have been found in mammalian cells [6,7]. They are all participated in cell cycle regulation transcriptional repression, heterochromatin, and apoptosis [8, 9]. Depending on the basic molecular structure pattern of the CBXs, they can be split into the heterochromatin protein 1 (HP1) group (CBX1/3/5, also known as $\mathrm{HP} 1 \beta / \gamma / \alpha)$ and the polycomb (PC) group (CBX2/4/6/7/8) [10, 11]. The CBX family had been reported to regulate the occurrence and development of a variety of tumors by limiting self-renewal and 
differentiation of tumor stem cells [12]. Emerging studies showed the dysregulated CBX members in multiple cancer types, including ovarian cancer [13], cervical cancer [14], pancreatic cancer [15], lung cancer [16], liver cancer [17], esophageal squamous cell carcinoma [18], breast cancer [19, 20] and gastric cancer [21] and so on. However, the precise functions of distinct $\mathrm{CBX}$ members in the development and progression of GBM remain elusive.

Therefore, in this work, we used multiple large public databases to explore the expression profiles, clinical relationships, prognostic implications, and immune infiltration of CBXs in GBM. We also investigated the predicted functions and pathways of the CBX family and their co-expressed genes. Our data highlighted the potential application value and mechanisms of CBXs in the prognosis and treatment of GBM.

\section{RESULTS}

\section{Differential expression of CBXs in patients with GBM}

To investigate the differential expression of distinct CBX family members in patients with GBM, mRNA expression and protein expression were analyzed with different databases. Firstly, according to the data acquired from GEPIA2, the mRNA expression levels of CBX2/3/5/8 were remarkably up-regulated in GBM tissues, while the mRNA expression levels of CBX6 and CBX7 were down-regulated in GBM tissues. However, the mRNA levels of CBX1 and CBX4 showed no difference between GBM tissues and normal glial tissues (Figure 1A). Then, the transcriptional levels of CBX family were further explored using UALCAN database and similar results were obtained. The results also showed elevated levels of $\mathrm{CBX} 2 / 3 / 5 / 8$, while reduced levels of CBX6 and $\mathrm{CBX} 7$ in GBM tissues vs. normal glial tissues. Besides, $\mathrm{CBX} 4$ was found to be down-regulated in GBM tissues (Figure 1B). Furthermore, we compared the relative expression of CBX members in GBM using GEPIA2 database and found that $\mathrm{CBX} 3$ had the highest and $\mathrm{CBX} 2$ had the lowest relative mRNA levels among all eight CBX members (Figure 1C).

After determining the transcriptional expression of distinct CBX members in GBM, we then explored the immunohistochemistry (IHC) data about the protein expression patterns of CBX members in GBM using the Human Protein Atlas. The results exhibited that $\mathrm{CBX} 2 / 3 / 5 / 8$ protein expression levels were higher in GBM tissues (Figure 2B, 2C, 2E, 2H), while CBX4 protein level was lower in GBM tissues (Figure 2D). Additionally, the protein level of $\mathrm{CBX} 1$ showed no obvious difference between GBM tissues and paired normal glial tissues (Figure 2A). These results were consistent with our previous results on the CBXs mRNA expression. However, the protein levels of CBX6 and CBX7 were not observed in both GBM tissues and paired normal tissues and showed no significant difference (Figure 2F, 2G). This may be because the baseline expression of $\mathrm{CBX} 6 / 7$ in normal tissues was already very low, so it is hard to detect lower CBX6/7 expression in GBM tumor tissues.

\section{Clinicopathological parameters of CBXs in patients with GBM}

After a comprehensive analysis of each CBX member expression pattern, the relationships between the expression of differentially expressed CBX members and tumor grade and recurrence status in GBM were further investigated using the GlioVis database. As illustrated in Figure 3A, the mRNA levels of $\mathrm{CBX} 2 / 3 / 6 / 7 / 8$ were related to tumor grades, but the mRNA expressions of CBX1/4/5 were not markedly different. Statistically, the mRNA expression of $\mathrm{CBX} 2 / 3 / 8$ tended to be higher as tumor grade increased, whereas the mRNA expression of CBX6/7 tended to be lower with increasing tumor grade. The highest mRNA levels of $\mathrm{CBX} 3 / 8$ were observed in tumor grade IV, whereas the highest mRNA levels of CBX6/7 were detected in tumor grade II. Notably, CBX2 had a lower mRNA expression level in tumor grade IV compared to tumor grade III, and the highest mRNA levels of CBX2 were exhibited in tumor grade III.

Moreover, we then investigated the correlation between the expression of each $\mathrm{CBX}$ member and recurrence status in GBM. As shown in Figure 3B, except for CBX7, the mRNA levels of CBX1/2/3/4/5/6//8 was all significantly associated with tumor recurrence status. Those CBX members had higher expression levels in recurrent tumors compared to primary tumors. The above findings were almost consistent with our previous results on CBXs expression, except for CBX4/6 whose expression levels were lower in GBM tumor tissues. Summarily, based on these findings on the expression profiles of CBX members and the relationships between CBXs expression and clinicopathological parameters, CBX2/3/8 might play critical roles in the tumorigenesis and recurrence of GBM.

\section{Prognostic value of mRNA level of CBXs in patients with GBM}

To investigate the worth of the CBXs in the progression of GBM, we applied the GlioVis database to analyze correlations between differentially expressed CBXs and clinical outcomes. As shown in Figure 4, overexpression of $\mathrm{CBX} 3 / 8$ was correlated to a short 
survival time, whereas higher expression of CBX6 was significantly correlated to a longer survival time. In addition, the rest of the CBX members did not seem to be associated with survival time in patients with GBM.
Thus, the mRNA expression levels of CBX3/6/8 were obviously associated with the prognosis of GBM and could potentially be applied as a useful predictive biomarker. Conclusively, based on our comprehensive
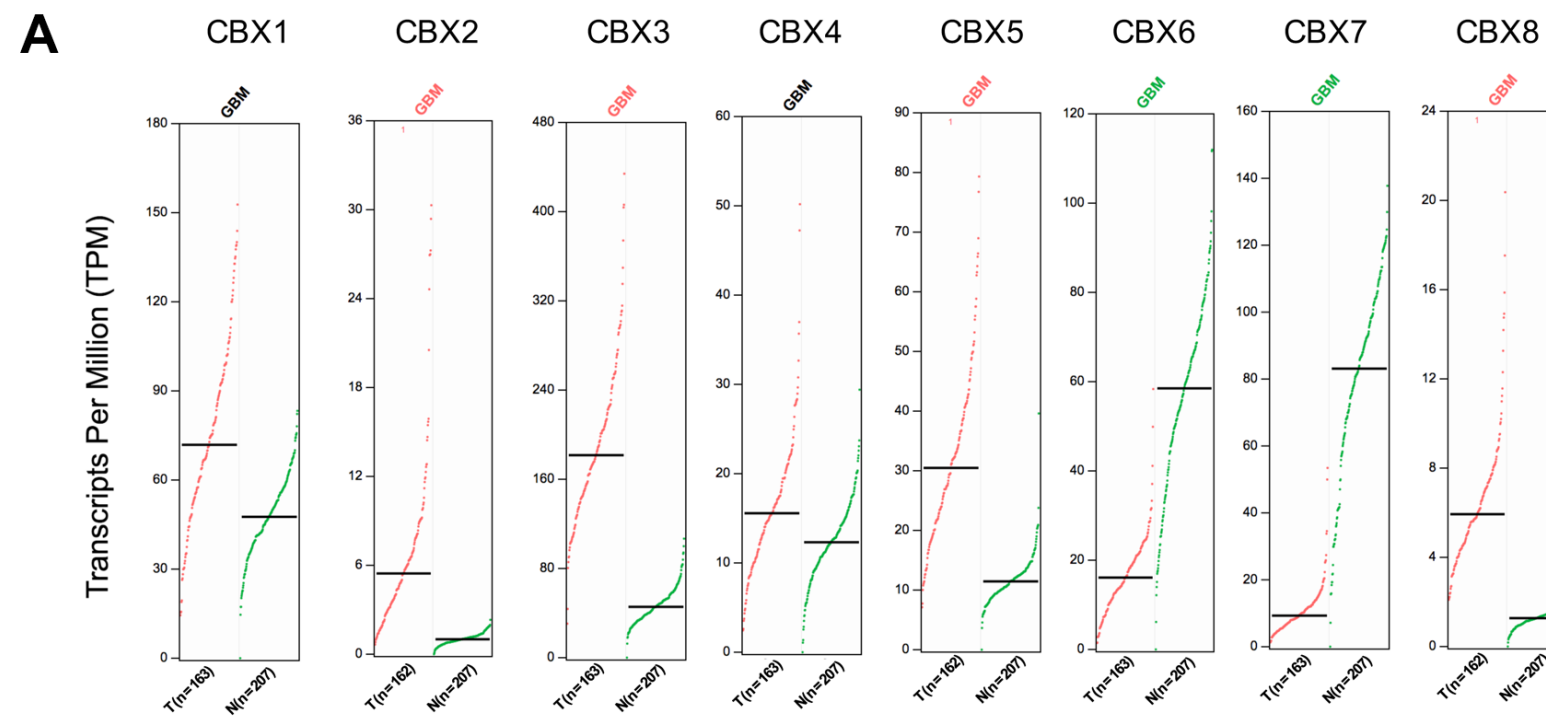

B

CBX1
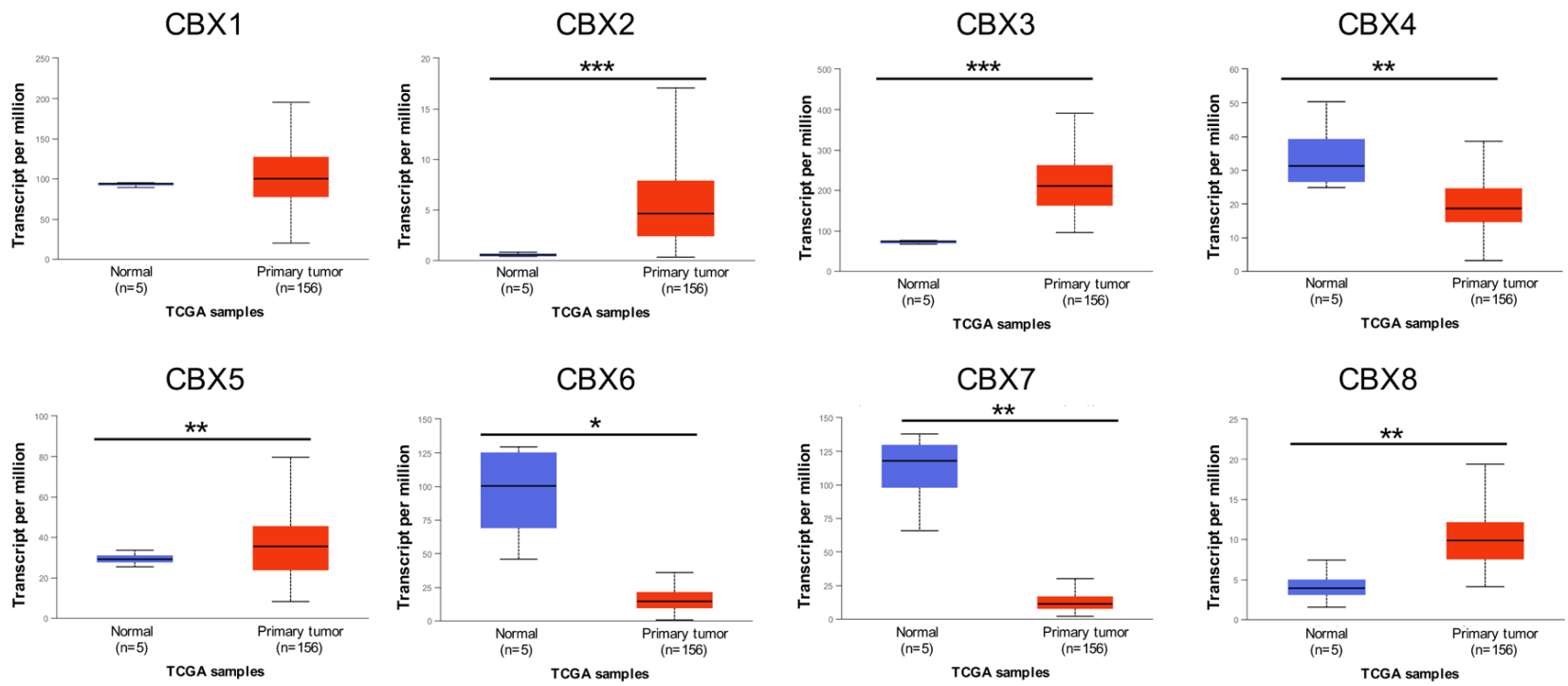

C

$6^{835}$

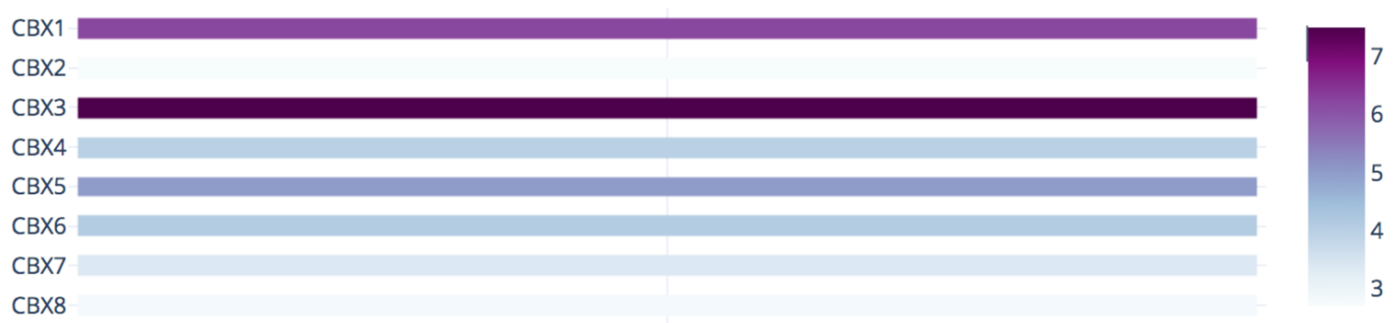

Figure 1. mRNA expression levels of CBXs in GBM. (A) mRNA expression levels of eight CBXs in GBM tissues and normal glial tissues from the GEPIA2. T: GBM tissues; N: normal tissues. (B) mRNA expression levels of eight CBXs in GBM tissues and normal glial tissues from the UALCAN. (C) The relative expression of eight CBX members in GBM. ${ }^{*} p<0.05,{ }^{* *} p<0.01, * * * p<0.001$. 
analysis of the expression, clinicopathological parameters, and prognostic values of eight CBX members, CBX3 and CBX8 were identified and might play pivotal roles in the tumorigenesis and progression of glioblastoma.

\section{CBX8 promoted the proliferation of glioma cells}

Several works have explored the function of CBX8 in GBM. Whereas the role of CBX8 in GBM has not been

A

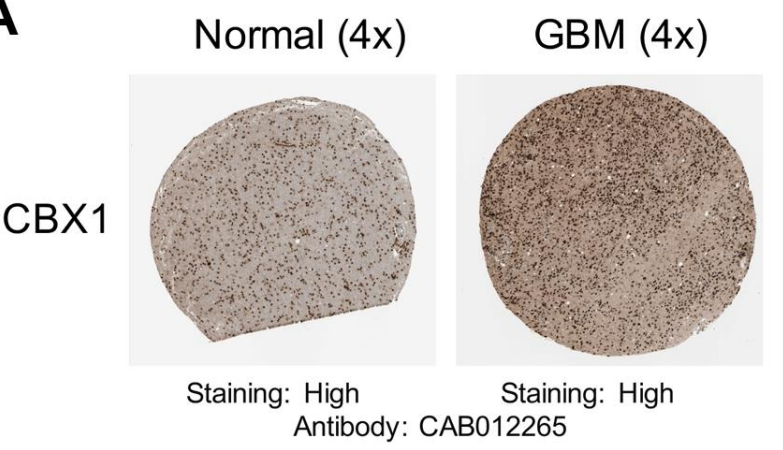

C

CBX3

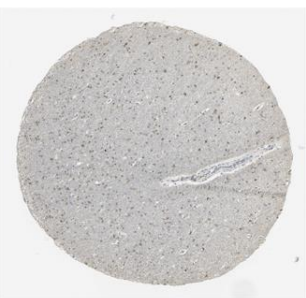

Staining: Medium

Antibody: HPA004902

E

CBX5

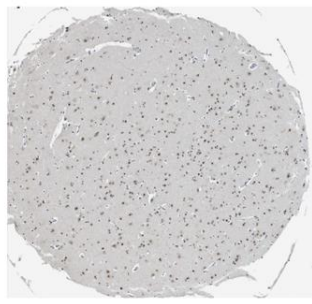

Staining: Low Antibody: CAB017548

G

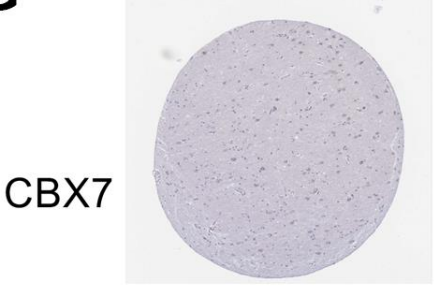

Staining: Not detected
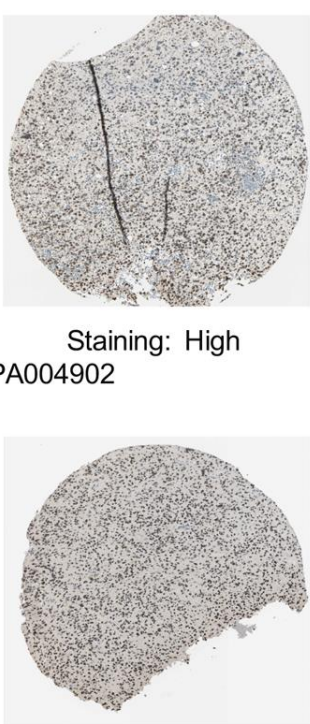

Staining: High

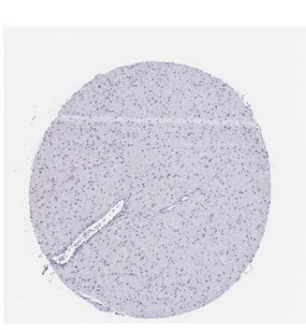

Staining: Not detected HPA056480
B

CBX2

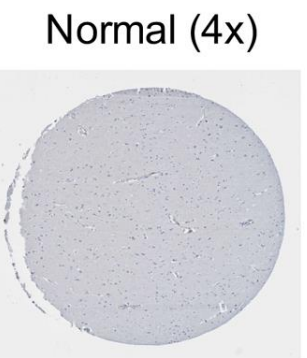

Staining: Not detected Antibody: HPA023083

GBM (4x)

D

CBX4

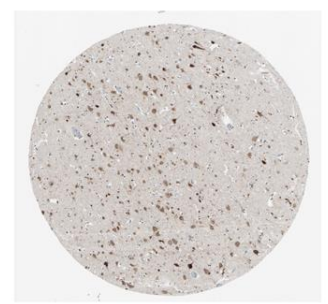

Staining: High Antibody: HPA008228

$\mathbf{F}$

CBX6

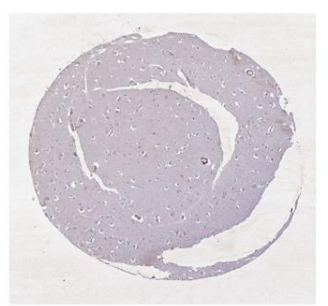

Staining: Not detected Antibody: HPA048653

H

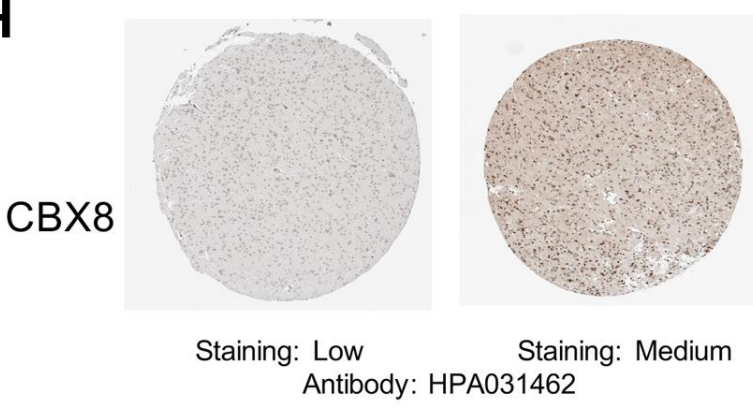

Figure 2. Representative immunohistochemistry images of CBXs from The Human Protein Atlas. (A-H) The protein expression profiles of eight CBXs in GBM tissues and normal glial tissues. 

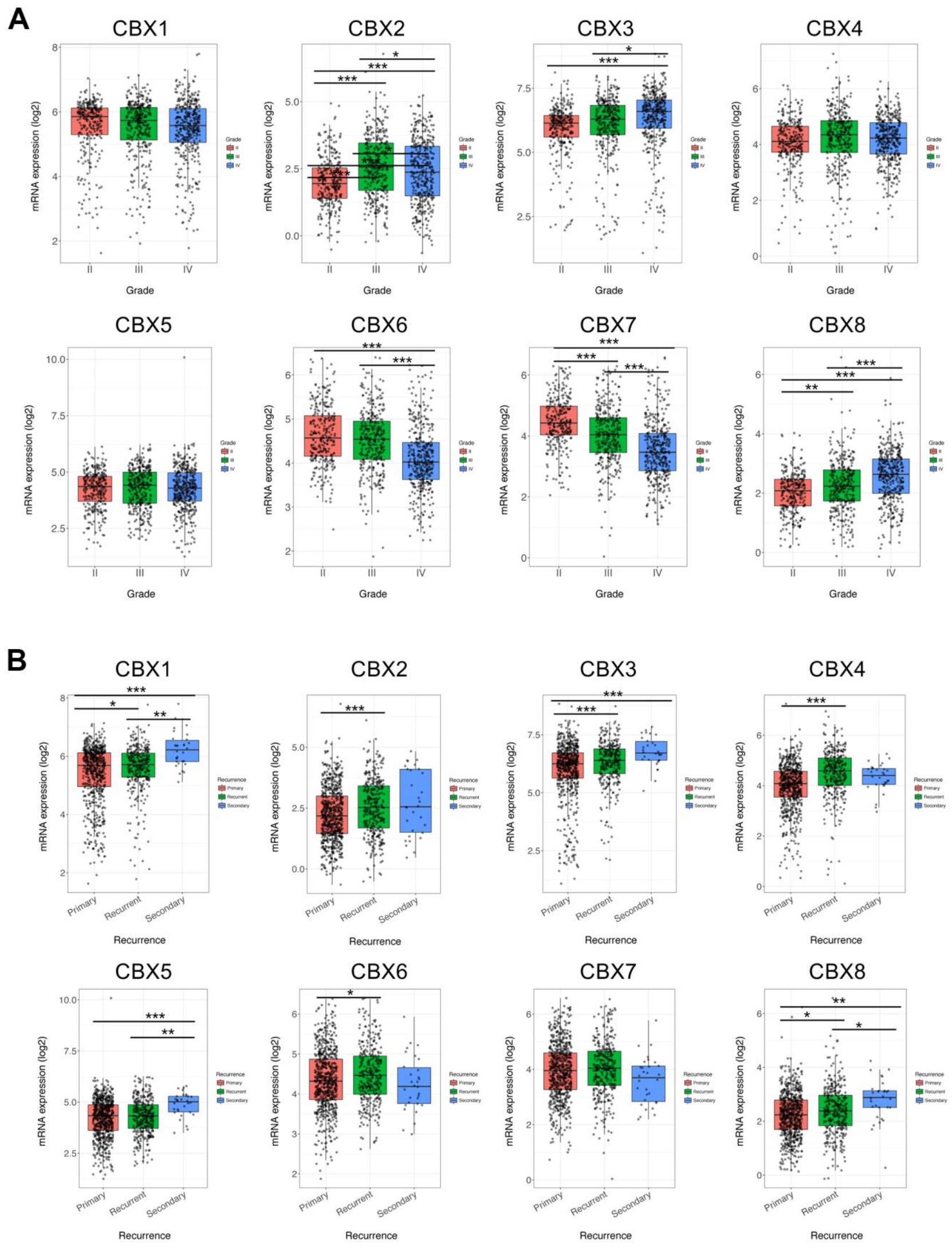

Figure 3. Association of CBXs transcript levels with clinical pathology. (A) Relationships between mRNA expression levels of eight CBX members and tumor grades of GBM. (B) Relationships between mRNA expression levels of eight CBX members and recurrent status of GBM. Analyses were conducted using GlioVis. ${ }^{*} p<0.05,{ }^{* *} p<0.01,{ }^{* * *} p<0.001$. 
of CBX8 with siCBX8. Then, using the CCK-8 assay, we found that $\mathrm{CBX} 8$ knockdown suppressed the proliferation of glioma cells with siCBX8 (Figure 5D, $5 \mathrm{E})$. These findings suggested that $\mathrm{CBX} 8$ promoted the proliferation of glioma cells.

\section{Genetic alteration and functional analysis of CBXs in patients with GBM}

We explored the genetic alterations of CBXs in GBM using the cBioPortal. As shown in Figure 6A, the CBXs gene was altered in 50 samples from 136 glioblastoma patients, accounting for a $37 \%$ alteration rate. According to the TCGA Firehose Legacy dataset, the percentages of genetic alterations in CBX1-8 were $6,6,15,7,7,4,4$, and $7 \%$, respectively, in GBM (Figure 6A). Next, we evaluated the correlation of distinct CBX members with each other through analyzing their mRNA expression. As shown in Figure 6B, several significant positive correlations were found: $\mathrm{CBX} 1$ with $\mathrm{CBX} 2, \mathrm{CBX} 5$, and CBX8; $\mathrm{CBX} 2$ with $\mathrm{CBX} 4$ and $\mathrm{CBX} 8$; $\mathrm{CBX} 6$ with $\mathrm{CBX} 7$. Besides, the $\mathrm{CBX}$ with significant negative correlation was shown: CBX3 with CBX7 (Figure 6B).
Furthermore, we explored the function of the CBXs in GBM patients. We applied the cBioPortal to obtain 103 co-expressed genes that were most relevant with CBXs in GBM and used the Cytoscape to construct a proteinprotein interaction (PPI) network (Supplementary Table 2). As shown in Figure 7A, HOXC10, IRX1, HOXC11, and TBX5 were primarily related to the function of the CBXs in GBM (Figure 7A). Then, the functions of the $\mathrm{CBX}$ members and their frequently altered neighbor genes and the molecular mechanisms by which CBX family regulated glioblastoma were subsequently analyzed in the WebGestalt. Gene Ontology (GO) functional annotation included biological process (BP), cellular component (CC), and molecular function (MP), and the results showed that $\mathrm{CBX}$ proteins were primarily associated with biological regulation and metabolic process in BP. As for CC, the CBX proteins were mainly associated with the membrane and nucleus. Besides, the CBXs influenced MF through protein binding and ion binding (Figure 7B). As shown in Figure $7 \mathrm{C}$, the KEGG pathways involved in these coexpressed genes were subsequently explored and nine pathways were of significance. We discovered that
A

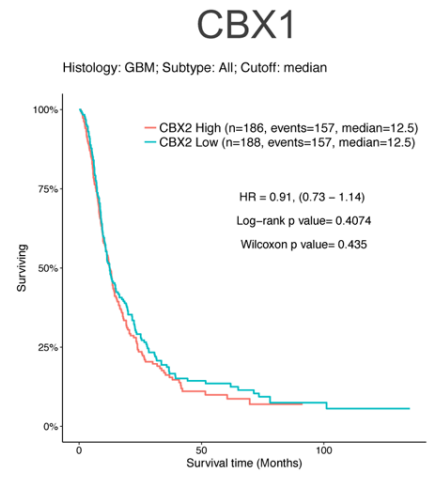

E

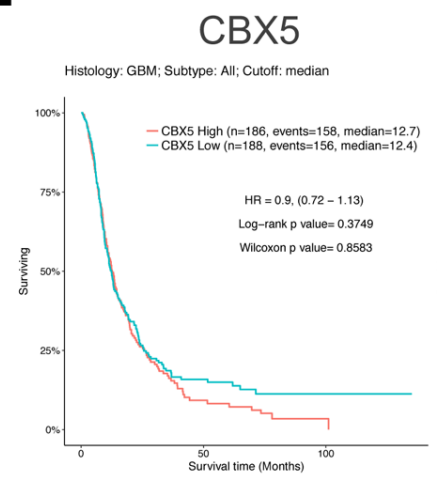

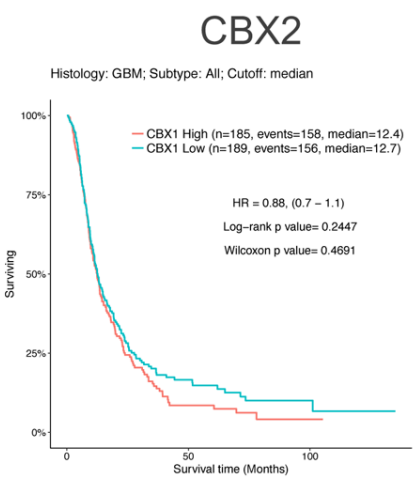

B

$\mathbf{F}$

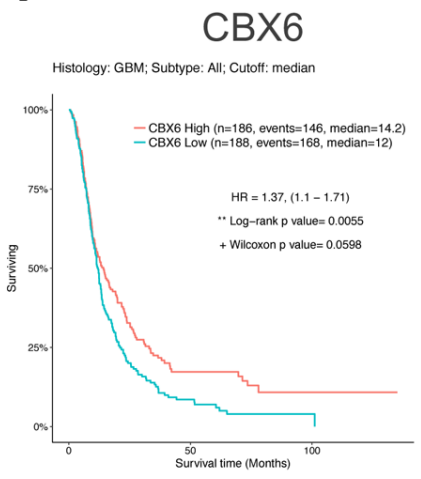

C

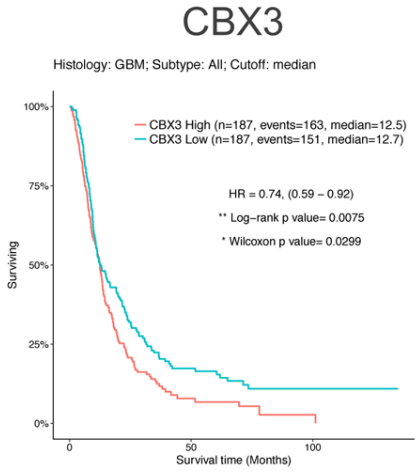

G

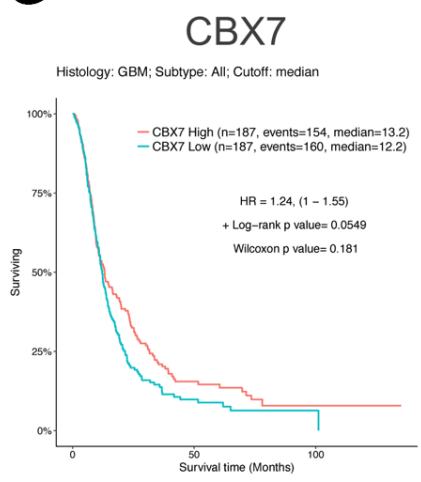

D

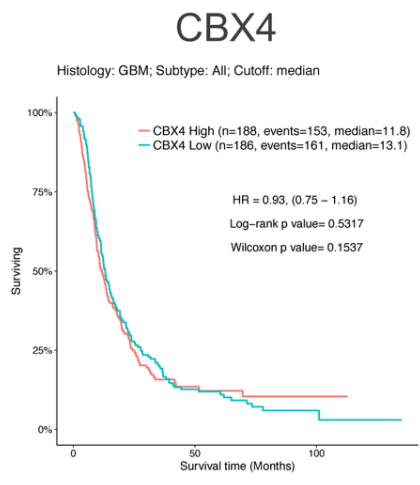

H

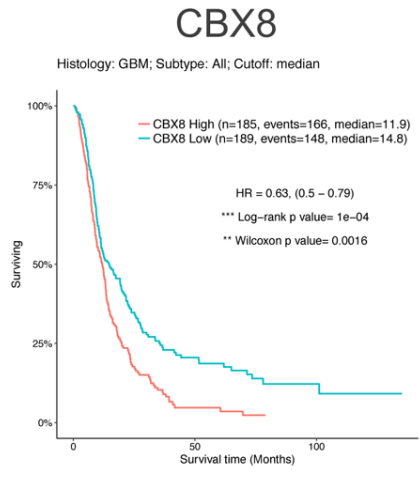

Figure 4. Prognostic value of CBXs transcript levels in GBM. (A-H) Relationships between mRNA expression levels of eight CBX members and the prognosis of patients with GBM. Analyses were conducted using the GlioVis. 
these co-expressed genes were primarily involved in signaling pathways of embryonic skeletal system development and chemical synaptic transmission, postsynaptic (Figure 7C).

\section{Immune cell infiltration of CBXs in patients with GBM}

Emerging evidence supported that immune cell levels were correlated with tumorigenesis and progression in multiple tumor types [7, 22]. In this analysis, through the TIMER2.0, we investigated the correlations between different CBX members and immune cell infiltration levels in GBM. As shown in Figure 8 and Supplementary Figure 1, CBX1/2 was both positively related to $\mathrm{B}$ cells and $\mathrm{CD} 4+\mathrm{T}$ cells, $\mathrm{CBX} 1$ was also negatively related to macrophages and $\mathrm{CBX} 2$ was negatively related to neutrophils (Figure 8A, 8B). Besides, CBX3/4 were both related to $\mathrm{CD} 8+$ and $\mathrm{CD} 4+$ T cells: $\mathrm{CBX} 3$ was positively related to $\mathrm{CD} 8+\mathrm{T}$ cells and was negatively associated with $\mathrm{CD} 4+\mathrm{T}$ cells, whereas CBX4 had the opposite trend (Figure 8C, 8D). In addition, $\mathrm{CBX} 5 / 6$ were both positively related to CD4+ $\mathrm{T}$ cells and dendritic cells and were negatively related to $\mathrm{CD} 8+\mathrm{T}$ cells and macrophages, CBX5 was also positively correlated with B cells (Figure 8E, 8F).
A

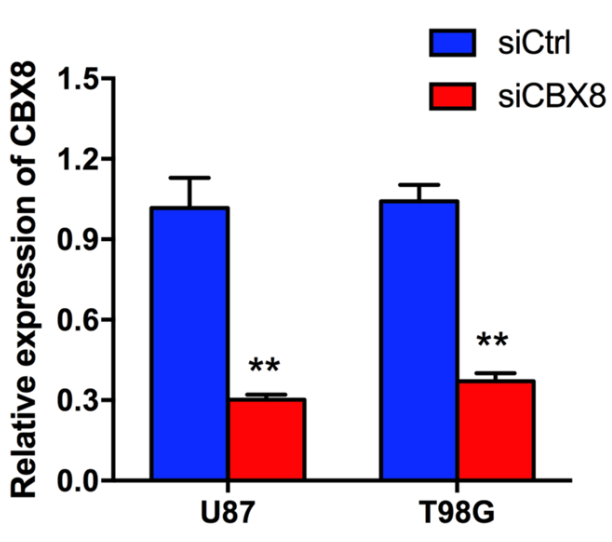

B
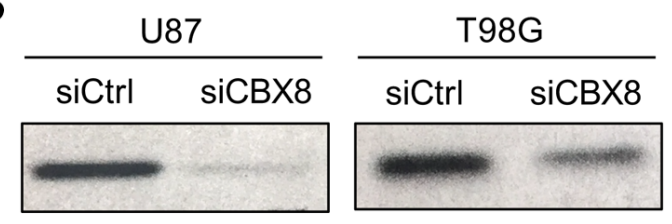

CBX8
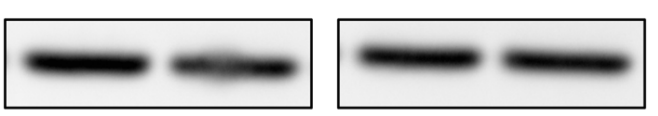

GAPDH

C

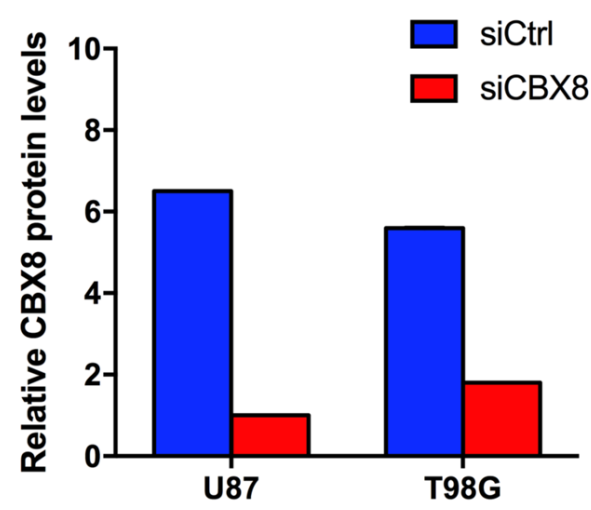

D

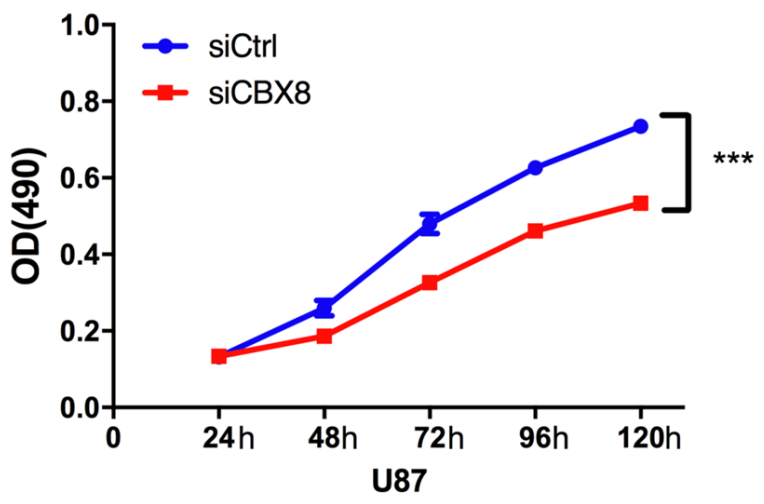

E

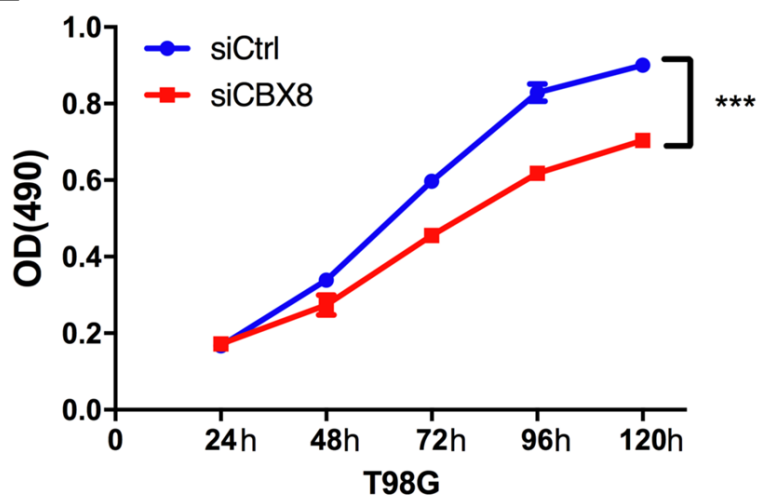

Figure 5. CBX8 promoted the proliferation of glioma cells. (A) The mRNA levels of CBX8 in U87 and T98G cells transfected with siCtrl and siCBX8. (B, C) The protein levels of CBX8 in U87 and T98G cells transfected with siCtrl and siCBX8. (D, E) The CCK-8 assay was applied to measure the effect of siCBX8 on the growth of U87 and T98G cells. $* * p<0.01, * * * p<0.001$. 
Moreover, $\mathrm{CBX} 7$ was negatively related to $\mathrm{CD} 8+\mathrm{T}$ cells and was positively related to the infiltration of four immune cells. These cells included B cells, dendritic cells, neutrophils, and CD4+ $\mathrm{T}$ cells (Figure 8G). However, CBX8 showed no correlations with the infiltration of these immune cells (Figure $8 \mathrm{H}$ ).

\section{Methylation expression levels of CBXs in patients with GBM}

DNA methylation has been found to be negatively correlated to the expression level of genes in various cancers [23, 24]. Here, we used the DiseaseMeth database to investigate the DNA methylation levels between GBM tissues and paired normal glial tissues. As shown in Supplementary Figure 2, the methylation levels of CBX7 were increased in GBM tissues. Our previous mRNA expression data showed the down-regulated expression of $\mathrm{CBX} 7$ in GBM tissues, and its reduced expression levels in GBM tissues might be because of its high methylation levels. However, except for CBX7, the methylation levels of other CBXs did not have a significant difference between GBM tumor tissues and paired normal glial tissues (Supplementary Figure 2), and
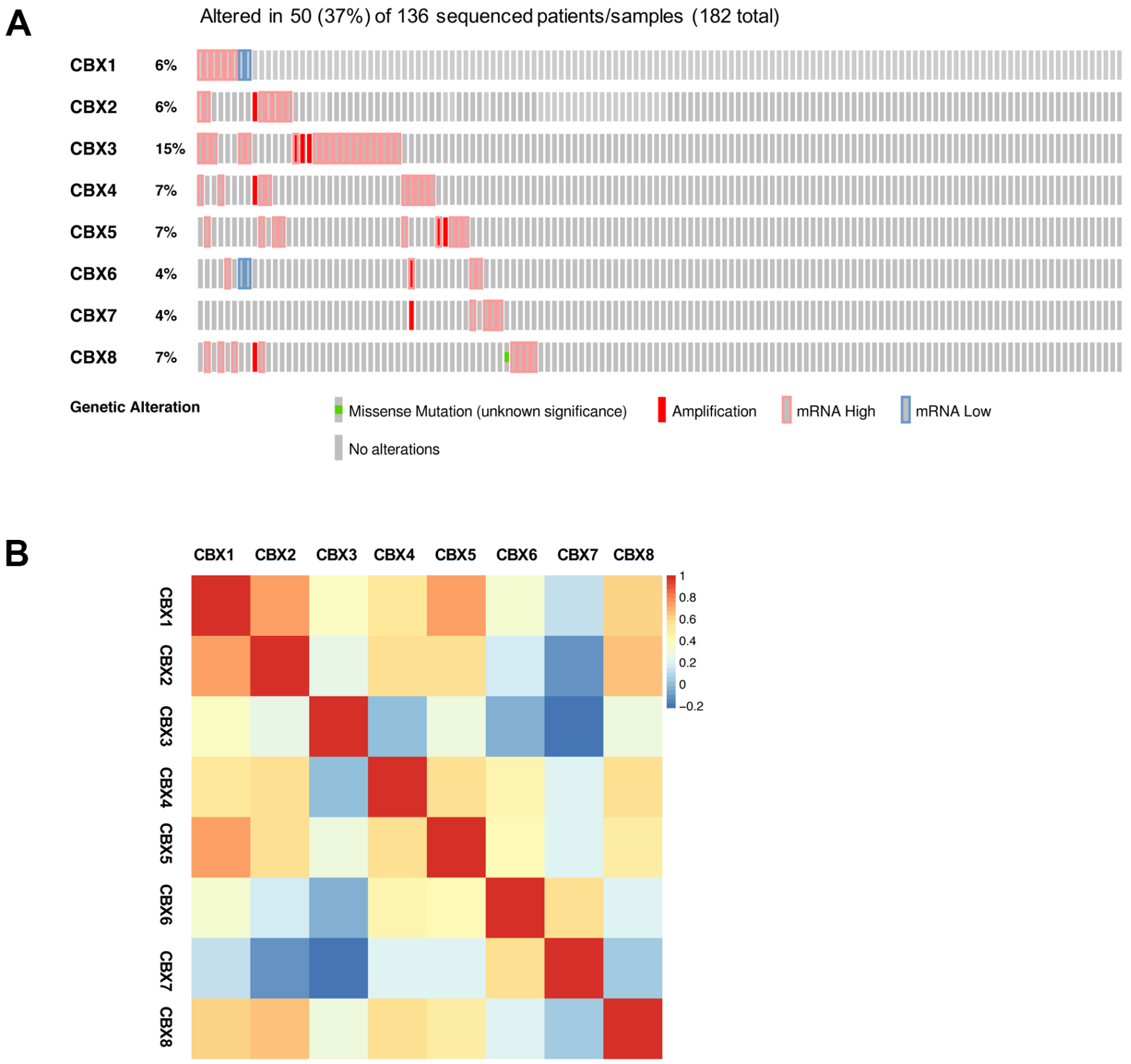

Figure 6. Genetic alterations and correlation analysis of CBXs in GBM. (A) summary of eight CBX member alteration in GBM (cBioPortal). (B) Correction of eight CBX members with each other (GEPIA2). 
A

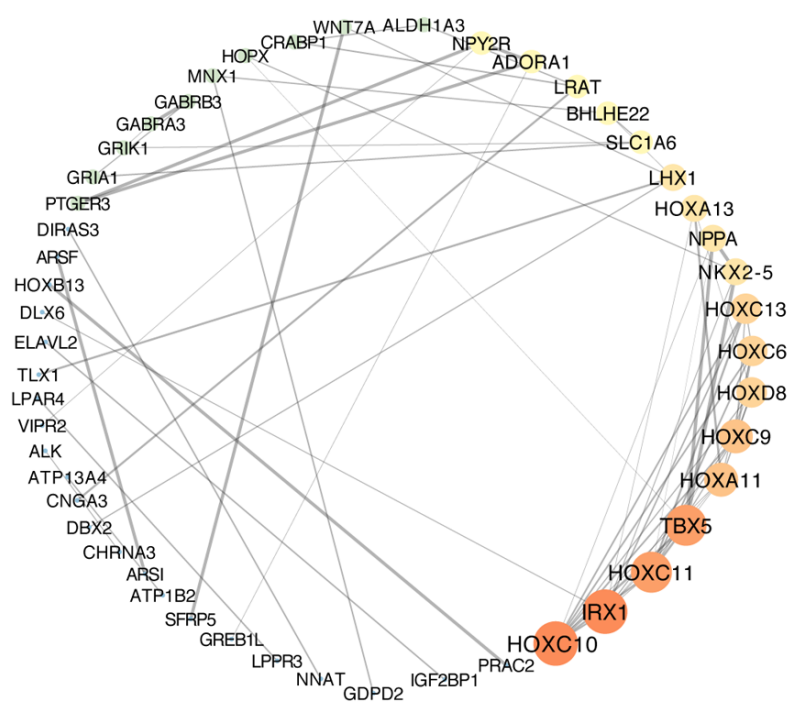

B
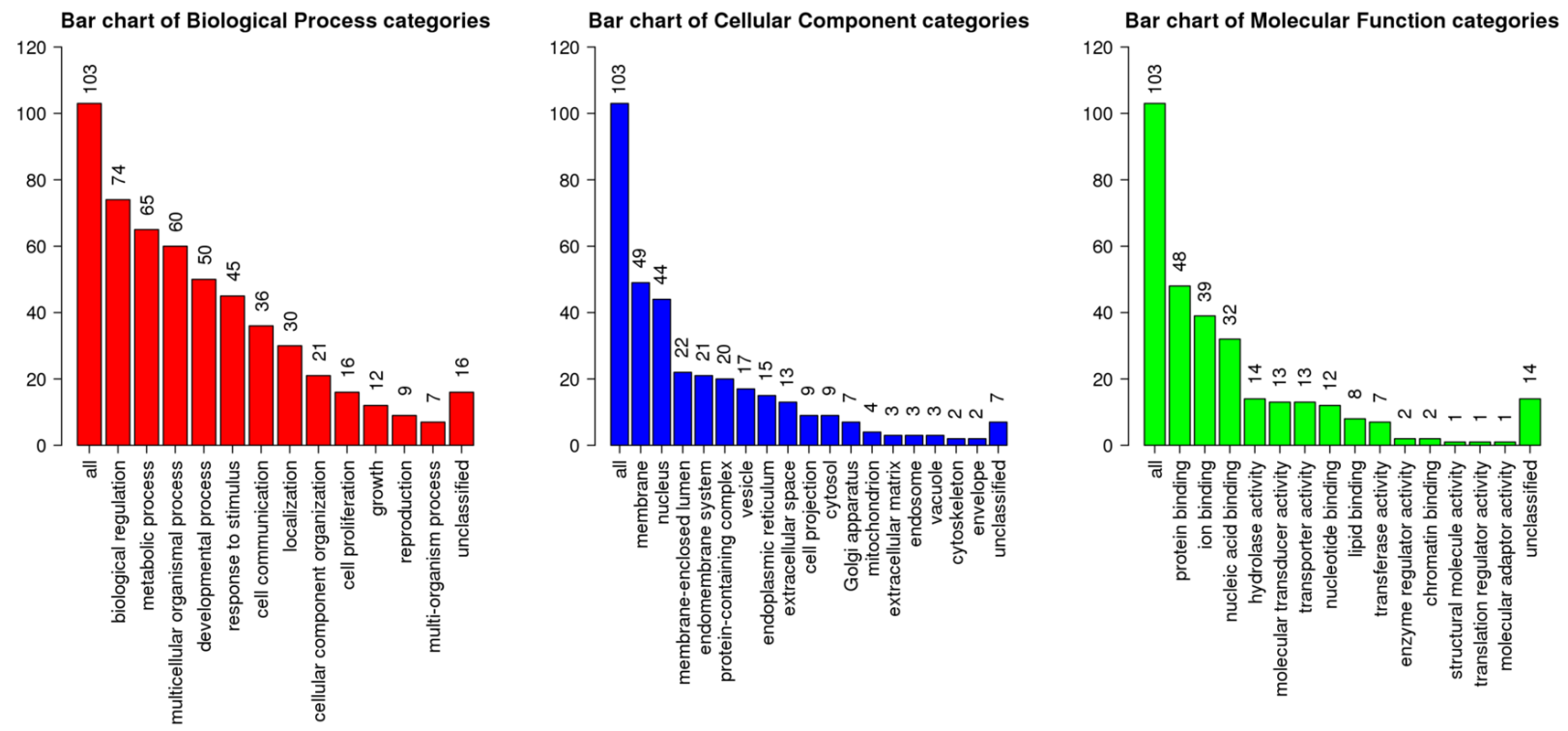

C

FDR $\leqslant 0.05 \quad F D R>0.05$

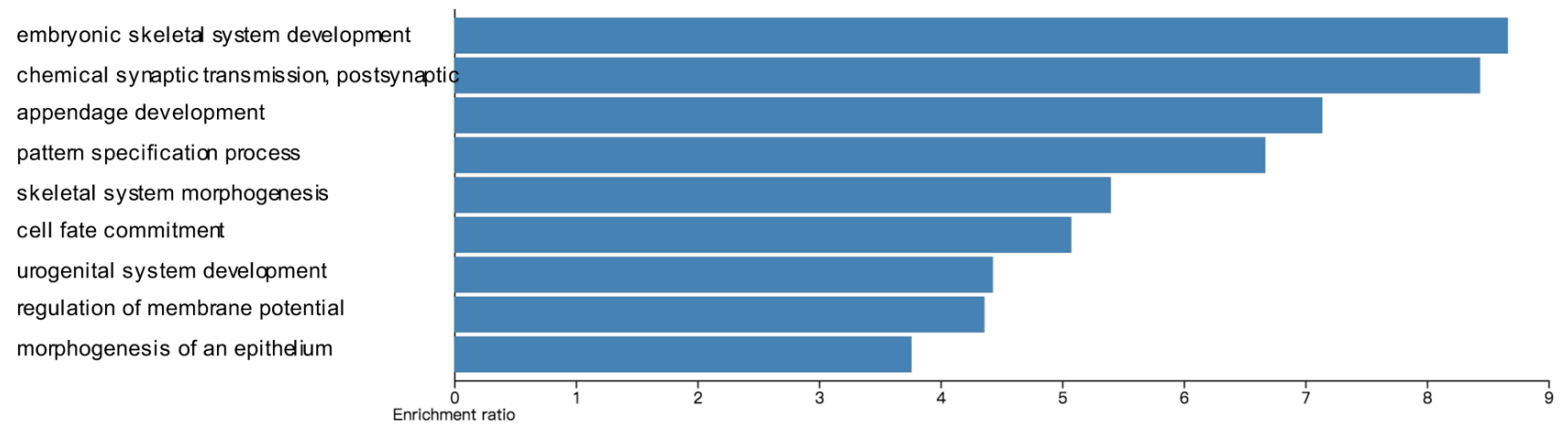

Figure 7. Predicted protein-protein interactions, functions, and pathways of CBXs and their co-expressed genes in GBM. (A) Protein-protein interaction (PPI) enrichment analysis of the 103 co-expressed genes of CBXs was constructed in cBioPortal and Cytoscape. The color of nodes: low values to bright colors; high values to dark colors. The thickness of edges: low values to fine edges; high values to thick edges. (B) Gene Ontology (GO) functional enrichment analysis of CBXs co-expressed genes (WebGestalt), including biological process, cellular components, and molecular functions. (C) Kyoto Encyclopedia of Genes and Genome (KEGG) analysis of CBXs co-expressed genes (WebGestalt). 


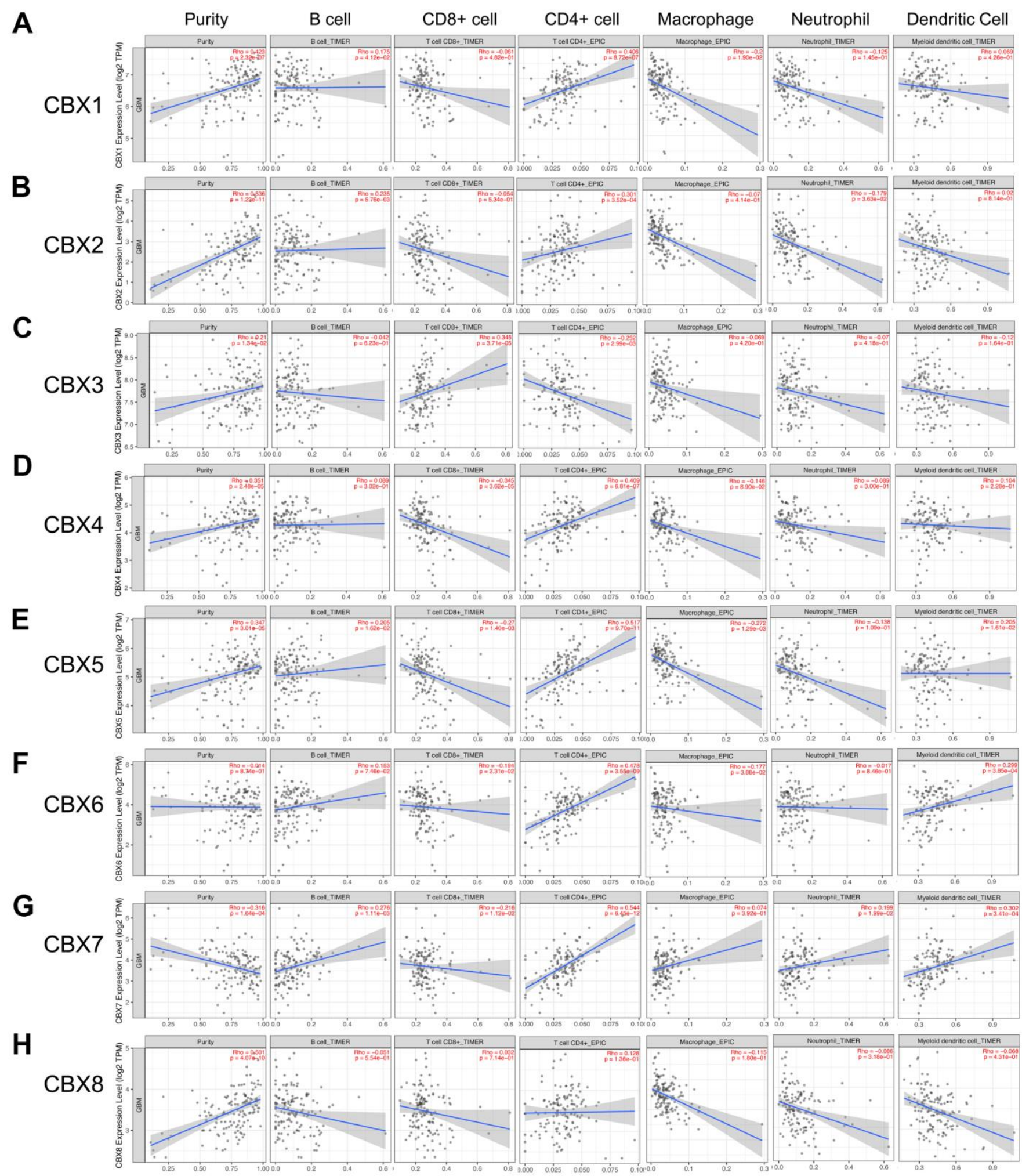

Figure 8. Correlations between CBXs and immune cell infiltration (TIMER2.0). (A-H) The effects of eight CBX members on the infiltration of six immune cells including B cells, CD8+ T cells, CD4+ T cells, macrophages, neutrophils, and dendritic cells. Each dot in the scatter plots represented a single tumor sample. 
there may be other correlated factors affecting their expression levels, such as posttranscriptional regulation, genetic alterations, and so on.

\section{DISCUSSION}

Glioblastoma is an aggressive primary malignant brain tumor, accounting for about $54.9 \%$ of all gliomas [2527]. Emerging evidence indicated that epigenetic alterations were frequently detected in various cancers and played a pivotal role in tumorigenesis and progression of these cancers [28]. Epigenetic alterations contained aberrant histone modifications, abnormal DNA methylation, and regulated several non-coding RNAs expression [29]. Moreover, Polycomb group $(\mathrm{PcG})$ proteins, as a class of epigenetic regulators, played a critical role in Polycomb inhibitory complexes (including PRC1 and PRC2) and were involved in the regulation of aging, cell proliferation, and tumorigenesis [30]. Hence, CBX members, which serve as the normative component of PRC1, may be related to epigenetic regulation through targeting PRC1 to chromatin [31]. To date, several CBX members were found to play important roles in several tumor types [18, 32], but the distinct roles of CBXs in GBM have not been fully elucidated. This study is the first time to comprehensively analyze their expression profiles, and explore their associations with the clinical features, prognostic implications, immune cell infiltration, methylation, and potential functions in GBM by using bioinformatics. We hoped that our work would help to improve early diagnosis and new therapeutic options in GBM patients.

For the first time, the transcriptional and protein expression levels of CBXs were summarized in GBM by using different databases. According to the data obtained from both GEPIA2 and UALCAN, we found elevated transcriptional expression levels of CBX2/3/5/8, while reducing levels of CBX6/7 in GBM tissues vs. normal tissues. Then, the protein levels of CBXs were further evaluated and the elevated protein expression levels of CBX2/3/5/8 were identified which was consistent with their mRNA expression pattern. However, the protein levels of $\mathrm{CBX} 6 / 7$ were not detected in both GBM tissues and paired normal tissues and showed no significant difference. Based on these findings above, CBX2/3/5/8 might play critical roles in the tumorigenesis and progression of GBM. Moreover, the relationships between the CBXs expression and tumor grade and recurrence status in GBM were further explored. The results exhibited that the mRNA expression of $\mathrm{CBX} 2 / 3 / 8$ tended to be higher as tumor grade increased, whereas the mRNA expression of CBX6/7 tended to be lower with increasing tumor grade. In addition, except for $\mathrm{CBX} 7$, the overexpression levels of CBX1/2/3/4/5/6//8 mRNA were detected in recurrent tumors compared to primary GBM tumors. Furthermore, we investigated the prognostic implications of the CBXs in the progression of GBM and found that overexpression of $\mathrm{CBX} 3 / 8$ mRNA, as well as underexpression of CBX6 mRNA, was significantly associated with shorter survival time. Summarily, based on our comprehensive analysis about the expression, clinicopathological parameters, and prognostic values of different CBXs, only CBX3 and $\mathrm{CBX} 8$, which got consistent results on all these aspects, were identified as likely to take a critical part in the development of glioblastoma.

Aberrant expression of $\mathrm{CBX} 3$ has been detected in several cancer types such as pancreatic cancer, osteosarcoma, colorectal cancer, breast cancer, and liver cancer. CBX3 has been found to be highly expressed and promote aerobic glycolysis by suppressing FBP1 in pancreatic cancer [33]. In patients with osteosarcoma, $\mathrm{CBX} 3$ is overexpressed which is associated with larger tumor sizes, higher metastasis rates, and poor prognosis [34]. In colorectal cancer, Liu et al. found that miR-30a could target CBX3 to inhibit colorectal cancer cell growth by a xenograft mouse model [35]. In breast cancer and liver cancer, CBX3 was identified to be highly expressed, and its overexpression could enhance tumor cell proliferation and predict a poor prognosis $[36,37]$. In our analysis, CBX3 was found to be highly expressed in GBM tissues, and its expression was obviously related to several clinicopathological parameters and poor prognosis in GBM. These outcomes highlighted that $\mathrm{CBX} 3$ may function as an oncogene and play a critical role in the tumorigenesis and development of GBM.

Existing evidences showed that $\mathrm{CBX} 8$ could regulate cell cycle progression, senescence, and differentiation in a variety of cancer types. In bladder cancer, CBX8 was found to inhibit the p53 pathway to enhance tumor cell proliferation, and its overexpression was positively associated with a poor prognosis [38]. In esophageal squamous cell carcinoma, Wang et al. found that CBX8 could promote tumor cell proliferation but inhibit cell metastasis by inhibiting Snail, and acted as a contradictory role [39]. Further verification was needed in the future to confirm its functionality. In hepatocellular carcinoma, $\mathrm{CBX} 8$ has been reported to exhibit oncogenic activity via $\mathrm{AKT} / \beta$-Catenin activation [40], and its overexpression was inversely correlated with patient survival time [17]. Yang et al. reported that down-regulated $\mathrm{CBX} 8$ could induce tumor cell apoptosis in colorectal cancer cells [41]. To date, there is no precise analysis exhibited the exact role of CBX8 in GBM. In this analysis, we exhibited that the expression levels of CBX8 were increased in GBM and 
positively correlated with higher tumor grade and recurrent status. Its overexpression levels represented a shorter survival time in patients with GBM. Besides, through CCK8 assay and transient transfection assay, we found that $\mathrm{CBX} 8$ promoted the proliferation of glioma cells. These data suggested that $\mathrm{CBX} 8$ might be a potential biomarker for glioblastoma, and guide clinical treatment.

Immune infiltration has become an increasingly popular topic and took a significant part in the progression and recurrence of various cancers [42, 43]. Immune cells have been reported to act as either tumor-suppressing or tumor-promoting activities. They were deemed to be a pivotal determinant of both the response to immunotherapy and the patient's clinical outcome [4446]. In this study, we found that except for CBX8, the expression of other seven CBX family members was obviously related to six immune cells infiltration, suggesting that distinct $\mathrm{CBX}$ family member might reveal the immune status in GBM patients in addition to the prognosis. Especially for $\mathrm{CD} 4+\mathrm{T}$ cells, the expression of CBX1-7 members were all related to its infiltration: the expression of $\mathrm{CBX} 3$ was negatively related to its infiltration, while the expression of CBX1/2/4/5/6/7 was positively related to its infiltration, suggesting that CD4 + T cells may play an essential role in the CBX family's influence on the immune status of GBM. Our findings might provide some useful immunization information to help design the new immunotherapy and improve patient prognosis.

However, we note some limitations in this study. Most of our data analyzed in this work was taken from online databases, further study consisting of clinical studies or more cell experiments would be required to validate our discoveries in vivo and in vitro.

\section{CONCLUSIONS}

In conclusion, we first systematically explored CBXs expression, its correlation with the clinical features, prognostic implications, immune cell infiltration, methylation, and potential functions in GBM, opening broad prospects for the potential of CBX members as prognostic markers and treatment targets of GBM. The elevated transcriptional expression of $\mathrm{CBX} 2 / 3 / 5 / 8$ and reduced expression of CBX6/7 were detected in GBM. The protein levels of $\mathrm{CBX} 2 / 3 / 5 / 8$ were higher while that of CBX6/7 showed no significant difference in GBM tissues. In addition, the upregulated expression of $\mathrm{CBX} 2 / 3 / 8$ and downregulation of $\mathrm{CBX} 6 / 7$ were discovered to be associated with the tumor grade. Except for CBX7, the overexpression levels of CBX1/2/3/4/5/6//8 mRNA were detected in recurrent tumors compared to primary GBM tumors. Moreover, overexpression of
CBX3/8 mRNA, as well as underexpression of CBX6 mRNA, was related to a shorter survival time. Moreover, through CCK8 assay and transient transfection assay, we found that CBX8 promoted the proliferation of glioma cells. Furthermore, a high genetic alteration rate of CBXs (37\%) was found in GBM and to varying degrees. The mRNA expression of CBXs was observed to be related to the infiltration of six immune cells, especially CD4 + T cells. The methylation levels of CBX7 were significantly increased in GBM which was consistent with its mRNA expression pattern. Our findings may provide new ideas to identify novel diagnostic and prognostic biomarkers among CBX members in glioblastoma.

\section{MATERIALS AND METHODS}

\section{GEPIA2}

GEPIA2 is an interactive web server using standard processing pipelines and analyzing the RNA sequencing expression data of thousands of cancer tissues and normal tissues from the TCGA and GTEx projects [47, 48]. In this work, we applied GEPIA2 to analyze the mRNA levels of CBXs between GBM tumor tissues and normal glial tissues. The $p$-value was generated by the Student's t-test. $|\log 2 \mathrm{FC}|>1$ and $p<0.01$ were significant. Besides, we also used the "correlation analysis" model of GEPIA2 to evaluate the correlation of the CBXs with each other. The databases applied in this work were summarized in Supplementary Table 1.

\section{UALCAN}

UALCAN is a comprehensive online platform containing the clinical data and level 3 RNA-seq data from TCGA database [49]. In this work, UALCAN was used to compare the transcriptional expression levels of distinct CBX members between GBM tissues and normal glial tissues.

\section{The Human Protein Atlas}

The Human Protein Atlas is an interactive online tool including transcriptome profiles and immunohistochemistry profiles for nearly 20 cancer types and thousands of patients [50]. In our analysis, we used immunohistochemical images downloaded from this database to compare the protein expression levels of distinct CBX members between GBM tumor tissues and normal glial tissues and evaluated their protein expression patterns in depth.

\section{GlioVis}

GlioVis is a powerful web application for the visualization and analysis of brain tumor expression 
datasets [51]. In our work, we used GlioVis to establish the correlation between mRNA expression levels of different CBX members and tumor grade and recurrent status of GBM. In addition, we also used this database to analyze the prognostic implications of CBXs mRNA expression in GBM. The Chinese Glioma Genome Atlas (CGGA) database containing over 600 glioma samples was chosen.

\section{cBioPortal}

cBioPortal is a comprehensive publicly web tool that could provide researchers with visual and multidimensional tumor genomics data $[52,53]$. In our study, the Glioblastoma Multiforme (TCGA, Firehose Legacy) dataset containing 604 samples was selected to analyze the CBXs in cBioPortal. We evaluated the genetic alterations and transcriptional expression of CBXs.

\section{Cytoscape}

Cytoscape is an open source software project for integrating models of biomolecular interaction networks [54]. In this analysis, we used Cytoscape to execute functional integration on 103 co-expressed genes of the CBXs obtained from the cBioPortal (Supplementary Table 2). The size of nodes represented the degree values of interacted proteins. The higher the degree, the larger the nodes.

\section{WebGestalt}

WebGestalt is a comprehensive and interactive gene set enrichment analysis toolkit that was used for gene lists interpretation. These gene lists can be derived from large scale -omics studies [55]. In our work, the KEGG pathway and GO enrichment were conducted by using this tool.

\section{TIMER2.0}

TIMER2.0 is a public web tool that could be used to analyze the relationships between cancers and immunity [56]. In this work, "Gene module" was applied and scatterplots were obtained to analyze the correlation between the expression levels of eight $\mathrm{CBX}$ members and the infiltrating of six immune cells in GBM.

\section{DiseaseMeth2.0}

DiseaseMeth2.0 is a kind of human disease methylation database that could present the most complete annotation and collection of abnormal DNA methylation in various human diseases, especially cancers $[57,58]$. In our study, the DNA methylation status of CBX members between GBM tumor tissues and normal glial tissues was evaluated by this database.

\section{Cells}

The glioma cell lines U87 and T98G were cultured as previously described [59].

\section{Transient transfection}

For transient transfections assay, siRNAs for CBX8 were purchased from Ribobio (SIGS0002853-4, Ribobio), and the transfection reagent used here was Lipofectamine 3000 reagent (Invitrogen). After the designated transfection times, the U87 and T98G cells were gathered and studied.

\section{RNA extraction and qRT-PCR analyses}

The process of RNA extraction and qRT-PCR was the same as previously described [13]. GAPDH was an internal control for quantification. The primer sequences of CBX8 were F: 5'ACGGAAAGGACGCATGGAAT3'; R: 5'CTTGGGTCCACGCTTTTTGG 3'.

\section{Western blot}

Protein samples were prepared and separated by SDSPAGE gels, transferred onto PVDF membrane, and blocked with 5\% non-fat milk. Then, blots were hybridized with the following primary antibodies: CBX8 (ab259849, Abcam), GAPDH (sc-47724, Santa Cruz Biotechnology). The detection of protein levels was conducted using Image Lab software (Bio-Rad, CA, USA).

\section{CCK8 assay}

The Cell Counting Kit-8 (Dojindo, Japan) was applied to detect cell growth according to the manufacturer's instructions.

\section{Statistical analyses}

Statistical analyses were performed with SPSS, version 18.0 (Chicago, USA). All experiments were performed in at least triplicate. The difference among groups was determined by Student's t-test. P < 0.05 was statistically significant.

\section{AUTHOR CONTRIBUTIONS}

Conception and design: $\mathrm{K} \mathrm{Hu}$ and $\mathrm{J} \mathrm{Li}$. Writing, review, and/or revision of the manuscript: $\mathrm{J} \mathrm{Li}, \mathrm{K} \mathrm{Hu}$, and $\mathrm{L}$ Zhou. 
Experiments complete: $\mathrm{J} \mathrm{Li}$ and $\mathrm{K} \mathrm{Hu}$. Administrative, technical, or material support: $\mathrm{Z} \mathrm{Xu}$ and $\mathrm{L}$ Zhou. All authors approved final version of manuscript.

\section{CONFLICTS OF INTEREST}

The authors declare that they have no conflicts of interest.

\section{FUNDING}

This study is supported by grants from National Natural Science Foundation of China (82103300, 82102743), Outstanding Postdoctoral Innovative Talents Foundation (2021RC2022), Youth Science Foundation of Xiangya Hospital (2020Q07).

\section{REFERENCES}

1. Wesseling P, Capper D. WHO 2016 Classification of gliomas. Neuropathol Appl Neurobiol. 2018; 44:139-50.

https://doi.org/10.1111/nan.12432 PMID:28815663

2. McCord M, Mukouyama YS, Gilbert MR, Jackson S. Targeting WNT Signaling for Multifaceted Glioblastoma Therapy. Front Cell Neurosci. 2017; 11:318.

https://doi.org/10.3389/fncel.2017.00318

PMID:29081735

3. Broekman ML, Maas SL, Abels ER, Mempel TR, Krichevsky AM, Breakefield XO. Multidimensional communication in the microenvirons of glioblastoma. Nat Rev Neurol. 2018; 14:482-95.

https://doi.org/10.1038/s41582-018-0025-8

PMID:29985475

4. Byun DJ, Wolchok JD, Rosenberg LM, Girotra M. Cancer immunotherapy - immune checkpoint blockade and associated endocrinopathies. Nat Rev Endocrinol. 2017; 13:195-207.

https://doi.org/10.1038/nrendo.2016.205

PMID:28106152

5. Bredel M, Bredel C, Juric D, Harsh GR, Vogel H, Recht LD, Sikic BI. Functional network analysis reveals extended gliomagenesis pathway maps and three novel MYC-interacting genes in human gliomas. Cancer Res. 2005; 65:8679-89.

https://doi.org/10.1158/0008-5472.CAN-05-1204 PMID:16204036

6. Dudakovic A, Gluscevic $M$, Paradise $C R$, Dudakovic $H$, Khani F, Thaler R, Ahmed FS, Li X, Dietz AB, Stein GS, Montecino MA, Deyle DR, Westendorf JJ, van Wijnen AJ. Profiling of human epigenetic regulators using a semi-automated real-time qPCR platform validated by next generation sequencing. Gene. 2017; 609:28-37. https://doi.org/10.1016/i.gene.2017.01.019 PMID:28132772

7. Zhou J, Chen Z, Zou M, Wan R, Wu T, Luo Y, Wu G, Wang W, Liu T. Prognosis and Immune Infiltration of Chromobox Family Genes in Sarcoma. Front Oncol. 2021; 11:657595.

https://doi.org/10.3389/fonc.2021.657595

PMID:34046352

8. Ning G, Huang YL, Zhen LM, Xu WX, Jiao $Q$, Yang FJ, Wu LN, Zheng YY, Song J, Wang YS, Xie C, Peng L. Transcriptional expressions of Chromobox 1/2/3/6/8 as independent indicators for survivals in hepatocellular carcinoma patients. Aging (Albany NY). 2018; 10:3450-73. https://doi.org/10.18632/aging.101658 PMID:30481161

9. Li Q, Pan Y, Cao Z, Zhao S. Comprehensive Analysis of Prognostic Value and Immune Infiltration of Chromobox Family Members in Colorectal Cancer. Front Oncol. 2020; 10:582667. https://doi.org/10.3389/fonc.2020.582667 PMID:33014884

10. Ruddock-D'Cruz NT, Prashadkumar S, Wilson KJ, Heffernan C, Cooney MA, French AJ, Jans DA, Verma PJ, Holland MK. Dynamic changes in localization of Chromobox ( $\mathrm{Cbx}$ ) family members during the maternal to embryonic transition. Mol Reprod Dev. 2008; 75:477-88. https://doi.org/10.1002/mrd.20752 PMID: 17486619

11. Kumar A, Kono $\mathrm{H}$. Heterochromatin protein 1 (HP1): interactions with itself and chromatin components. Biophys Rev. 2020; 12:387-400. https://doi.org/10.1007/s12551-020-00663-y PMID:32144738

12. Klauke K, Radulović V, Broekhuis M, Weersing E, Zwart E, Olthof S, Ritsema M, Bruggeman S, Wu X, Helin K, Bystrykh L, de Haan G. Polycomb Cbx family members mediate the balance between haematopoietic stem cell self-renewal and differentiation. Nat Cell Biol. 2013; 15:353-62. https://doi.org/10.1038/ncb2701 PMID:23502315

13. Li J, Alvero AB, Nuti $S$, Tedja R, Roberts $C M$, Pitruzzello M, Li Y, Xiao Q, Zhang S, Gan Y, Wu X, Mor G, Yin G. CBX7 binds the E-box to inhibit TWIST-1 function and inhibit tumorigenicity and metastatic potential. Oncogene. 2020; 39:3965-79.

https://doi.org/10.1038/s41388-020-1269-5 PMID:32205869

14. Li R, Yan $Q$, Tian $P$, Wang $Y$, Wang J, Tao N, Ning L, Lin $X$, Ding L, Liu J, Ma C. CBX7 Inhibits Cell Growth and Motility and Induces Apoptosis in Cervical Cancer Cells. Mol Ther Oncolytics. 2019; 15:108-16. 
https://doi.org/10.1016/j.omto.2019.09.002 PMID:31709304

15. Chen LY, Cheng CS, Qu C, Wang P, Chen H, Meng ZQ, Chen Z. Overexpression of $\mathrm{CBX} 3$ in Pancreatic Adenocarcinoma Promotes Cell Cycle TransitionAssociated Tumor Progression. Int J Mol Sci. 2018; 19:E1768.

https://doi.org/10.3390/ijms19061768

PMID:29903985

16. $\mathrm{Yu} Y \mathrm{YH}$, Chiou $\mathrm{GY}$, Huang $\mathrm{PI}$, Lo $\mathrm{WL}$, Wang $\mathrm{CY}$, Lu KH, Yu CC, Alterovitz G, Huang WC, Lo JF, Hsu HS, Chiou $\mathrm{SH}$. Network biology of tumor stem-like cells identified a regulatory role of CBX5 in lung cancer. Sci Rep. 2012; 2:584.

https://doi.org/10.1038/srep00584

PMID:22900142

17. Tang B, Tian Y, Liao Y, Li Z, Yu S, Su H, Zhong F, Yuan G, Wang Y, Yu H, Tomlinson S, Qiu X, He S. CBX8 exhibits oncogenic properties and serves as a prognostic factor in hepatocellular carcinoma. Cell Death Dis. 2019; 10:52.

https://doi.org/10.1038/s41419-018-1288-0

PMID:30718464

18. Zhang $\mathrm{Y}$, Chen $\mathrm{H}$, Zhu $\mathrm{H}$, Sun $\mathrm{X}$. CBX8 promotes tumorigenesis and confers radioresistance in esophageal squamous cell carcinoma cells through targeting APAF1. Gene. 2019; 711:143949.

https://doi.org/10.1016/i.gene.2019.143949 PMID:31255735

19. Zeng JS, Zhang ZD, Pei L, Bai ZZ, Yang Y, Yang H, Tian $\mathrm{QH}$. CBX4 exhibits oncogenic activities in breast cancer via Notch1 signaling. Int J Biochem Cell Biol. 2018; 95:1-8.

https://doi.org/10.1016/j.biocel.2017.12.006

PMID:29229426

20. Deng $H$, Guan X, Gong L, Zeng J, Zhang H, Chen MY, Li G. CBX6 is negatively regulated by EZH2 and plays a potential tumor suppressor role in breast cancer. Sci Rep. 2019; 9:197.

https://doi.org/10.1038/s41598-018-36560-4 PMID: 30655550

21. Lin H, Lian J, Xia L, Guan G, You J. CBX3 Promotes Gastric Cancer Progression and Affects Factors Related to Immunotherapeutic Responses. Cancer Manag Res. 2020; 12:10113-25.

https://doi.org/10.2147/CMAR.S271807 PMID:33116867

22. Chen Y, Lu W, Jin Z, Yu J, Shi B. Carbenoxolone ameliorates hepatic lipid metabolism and inflammation in obese mice induced by high fat diet via regulating the JAK2/STAT3 signaling pathway. Int Immunopharmacol. 2019; 74:105498. https://doi.org/10.1016/i.intimp.2019.03.011 PMID:31261036

23. Győrffy B, Bottai G, Fleischer T, Munkácsy G, Budczies J, Paladini L, Børresen-Dale AL, Kristensen VN, Santarpia L. Aberrant DNA methylation impacts gene expression and prognosis in breast cancer subtypes. Int J Cancer. 2016; 138:87-97. https://doi.org/10.1002/ijc.29684 PMID:26174627

24. Locke WJ, Guanzon D, Ma C, Liew YJ, Duesing KR, Fung KY, Ross JP. DNA Methylation Cancer Biomarkers: translation to the Clinic. Front Genet. 2019; 10:1150. https://doi.org/10.3389/fgene.2019.01150 PMID:31803237

25. Alexander BM, Cloughesy TF. Adult Glioblastoma. J Clin Oncol. 2017; 35:2402-9.

https://doi.org/10.1200/JCO.2017.73.0119 PMID:28640706

26. Taylor OG, Brzozowski JS, Skelding KA. Glioblastoma Multiforme: An Overview of Emerging Therapeutic Targets. Front Oncol. 2019; 9:963.

https://doi.org/10.3389/fonc.2019.00963

PMID:31616641

27. Yang J, Wang L, Xu Z, Wu L, Liu B, Wang J, Tian D, Xiong $X$, Chen $Q$. Integrated Analysis to Evaluate the Prognostic Value of Signature mRNAs in Glioblastoma Multiforme. Front Genet. 2020; 11:253.

https://doi.org/10.3389/fgene.2020.00253 PMID:32296458

28. Lee MP. Understanding Cancer Through the Lens of Epigenetic Inheritance, Allele-Specific Gene Expression, and High-Throughput Technology. Front Oncol. 2019; 9:794.

https://doi.org/10.3389/fonc.2019.00794 PMID:31497535

29. Qin T, Zhang X, Guo T, Yang T, Gao Y, Hao W, Xiao X. Epigenetic Alteration Shaped by the Environmental Chemical Bisphenol A. Front Genet. 2021; 11:618966. https://doi.org/10.3389/fgene.2020.618966 PMID:33505438

30. Di Croce L, Helin K. Transcriptional regulation by Polycomb group proteins. Nat Struct Mol Biol. 2013; 20:1147-55. https://doi.org/10.1038/nsmb.2669 PMID:24096405

31. Ma RG, Zhang Y, Sun $T T$, Cheng B. Epigenetic regulation by polycomb group complexes: focus on roles of CBX proteins. J Zhejiang Univ Sci B. 2014; 15:412-28. https://doi.org/10.1631/jzus.B1400077 PMID:24793759

32. Zhang H, Chen W, Fu X, Su X, Yang A. CBX3 promotes tumor proliferation by regulating $\mathrm{G} 1 / \mathrm{S}$ phase via $\mathrm{p} 21$ downregulation and associates with poor prognosis in 
tongue squamous cell carcinoma. Gene. 2018; 654:49-56.

https://doi.org/10.1016/j.gene.2018.02.043

PMID:29462646

33. Chen LY, Cheng CS, Qu C, Wang P, Chen H, Meng ZQ, Chen Z. CBX3 promotes proliferation and regulates glycolysis via suppressing FBP1 in pancreatic cancer. Biochem Biophys Res Commun. 2018; 500:691-7. https://doi.org/10.1016/i.bbrc.2018.04.137 PMID:29678579

34. Ma C, Nie XG, Wang YL, Liu XH, Liang X, Zhou QL, Wu DP. CBX3 predicts an unfavorable prognosis and promotes tumorigenesis in osteosarcoma. Mol Med Rep. 2019; 19:4205-12.

https://doi.org/10.3892/mmr.2019.10104 PMID:30942427

35. Liu $M$, Huang $F$, Zhang D, Ju J, Wu XB, Wang $Y$, Wang $Y$, Wu Y, Nie M, Li Z, Ma C, Chen X, Zhou JY, et al. Heterochromatin protein HP1 $y$ promotes colorectal cancer progression and is regulated by miR-30a. Cancer Res. 2015; 75:4593-604.

https://doi.org/10.1158/0008-5472.CAN-14-3735 PMID:26333808

36. Liang YK, Lin HY, Chen CF, Zeng D. Prognostic values of distinct CBX family members in breast cancer. Oncotarget. 2017; 8:92375-87.

https://doi.org/10.18632/oncotarget.21325 PMID:29190923

37. Zhong $X$, Kan A, Zhang W, Zhou J, Zhang H, Chen J, Tang S. CBX3/HP1 1 promotes tumor proliferation and predicts poor survival in hepatocellular carcinoma. Aging (Albany NY). 2019; 11:5483-97.

https://doi.org/10.18632/aging.102132

PMID:31375643

38. Yuan GJ, Chen X, Lu J, Feng ZH, Chen SL, Chen RX, Wei WS, Zhou FJ, Xie D. Chromobox homolog 8 is a predictor of muscle invasive bladder cancer and promotes cell proliferation by repressing the p53 pathway. Cancer Sci. 2017; 108:2166-75. https://doi.org/10.1111/cas.13383 PMID:28837252

39. Wang G, Tang J, Zhan W, Zhang R, Zhang M, Liao D, Wang $\mathrm{X}, \mathrm{Wu} \mathrm{Y}$, Kang T. CBX8 Suppresses Tumor Metastasis via Repressing Snail in Esophageal Squamous Cell Carcinoma. Theranostics. 2017; 7:3478-88. https://doi.org/10.7150/thno.20717 PMID:28912889

40. Zhang $\mathrm{CZ}$, Chen $\mathrm{SL}$, Wang $\mathrm{CH}$, He YF, Yang $X$, Xie D, Yun JP. CBX8 Exhibits Oncogenic Activity via AKT/ $\beta$-Catenin Activation in Hepatocellular Carcinoma. Cancer Res. 2018; 78:51-63. https://doi.org/10.1158/0008-5472.CAN-17-0700 PMID:29066512
41. Yang S, Liu W, Li M, Wen J, Zhu M, Xu S. Insulin-Like Growth Factor-1 Modulates Polycomb Cbx8 Expression and Inhibits Colon Cancer Cell Apoptosis. Cell Biochem Biophys. 2015; 71:1503-7. https://doi.org/10.1007/s12013-014-0373-y PMID:25398592

42. Paijens ST, Vledder A, de Bruyn M, Nijman HW. Tumorinfiltrating lymphocytes in the immunotherapy era. Cell Mol Immunol. 2021; 18:842-59. https://doi.org/10.1038/s41423-020-00565-9 PMID: $\underline{3139907}$

43. Cózar B, Greppi M, Carpentier S, Narni-Mancinelli E, Chiossone L, Vivier E. Tumor-Infiltrating Natural Killer Cells. Cancer Discov. 2021; 11:34-44. https://doi.org/10.1158/2159-8290.CD-20-0655 PMID:33277307

44. Shen $\mathrm{H}$, Sun $\mathrm{T}$, Hoang HH, Burchfield JS, Hamilton GF, Mittendorf EA, Ferrari $M$. Enhancing cancer immunotherapy through nanotechnology-mediated tumor infiltration and activation of immune cells. Semin Immunol. 2017; 34:114-22. https://doi.org/10.1016/i.smim.2017.09.002 PMID:28947107

45. Sokratous G, Polyzoidis S, Ashkan K. Immune infiltration of tumor microenvironment following immunotherapy for glioblastoma multiforme. Hum Vaccin Immunother. 2017; 13:2575-82. https://doi.org/10.1080/21645515.2017.1303582 PMID:28362548

46. Tang X, Xu P, Chen A, Deng G, Zhang S, Gao L, Dai L, Chen $Q$. Prognostic and Predictive Value of an Immunoscore Signature in Glioblastoma Multiform. Front Genet. 2020; 11:514363. https://doi.org/10.3389/fgene.2020.514363 PMID:33244317

47. Tang Z, Kang B, Li C, Chen T, Zhang Z. GEPIA2: an enhanced web server for large-scale expression profiling and interactive analysis. Nucleic Acids Res. 2019; 47:W556-60. https://doi.org/10.1093/nar/gkz430 PMID:31114875

48. Li J, Hu K, He D, Zhou L, Wang Z, Tao Y. Prognostic Value of PLXND1 and TGF- $\beta 1$ Coexpression and Its Correlation With Immune Infiltrates in Hepatocellular Carcinoma. Front Oncol. 2021; 10:604131. https://doi.org/10.3389/fonc.2020.604131 PMID:33489909

49. Chandrashekar DS, Bashel B, Balasubramanya SA, Creighton CJ, Ponce-Rodriguez I, Chakravarthi BV, Varambally S. UALCAN: A Portal for Facilitating Tumor Subgroup Gene Expression and Survival Analyses. Neoplasia. 2017; 19:649-58. 
https://doi.org/10.1016/i.neo.2017.05.002

PMID:28732212

50. Asplund A, Edqvist PH, Schwenk JM, Pontén F. Antibodies for profiling the human proteome-The Human Protein Atlas as a resource for cancer research. Proteomics. 2012; 12:2067-77. https://doi.org/10.1002/pmic.201100504 PMID:22623277

51. Bowman RL, Wang Q, Carro A, Verhaak RG, Squatrito M. GlioVis data portal for visualization and analysis of brain tumor expression datasets. Neuro Oncol. 2017; 19:139-41.

https://doi.org/10.1093/neuonc/now247

PMID:28031383

52. Cerami E, Gao J, Dogrusoz U, Gross BE, Sumer SO, Aksoy BA, Jacobsen A, Byrne CJ, Heuer ML, Larsson E, Antipin $Y$, Reva B, Goldberg AP, et al. The cBio cancer genomics portal: an open platform for exploring multidimensional cancer genomics data. Cancer Discov. 2012; 2:401-4. https://doi.org/10.1158/2159-8290.CD-12-0095 PMID:22588877

53. Li J, Hu K, Zhou L, Huang J, Zeng S, Xu Z, Yan Y. Spectrum of Mesenchymal-Epithelial Transition Aberrations and Potential Clinical Implications: Insights From Integrative Pancancer Analysis. Front Oncol. 2020; 10:560615. https://doi.org/10.3389/fonc.2020.560615 PMID:33178590

54. Doncheva NT, Morris JH, Gorodkin J, Jensen L. Cytoscape StringApp: Network Analysis and Visualization of Proteomics Data. J Proteome Res. 2019; 18:623-32. https://doi.org/10.1021/acs.jproteome.8b00702 PMID:30450911

55. Liao Y, Wang J, Jaehnig EJ, Shi Z, Zhang B. WebGestalt 2019: gene set analysis toolkit with revamped Uls and APIs. Nucleic Acids Res. 2019; 47:W199-205. https://doi.org/10.1093/nar/gkz401 PMID:31114916

56. Li T, Fu J, Zeng Z, Cohen D, Li J, Chen Q, Li B, Liu XS. TIMER2.0 for analysis of tumor-infiltrating immune cells. Nucleic Acids Res. 2020; 48:W509-14. https://doi.org/10.1093/nar/gkaa407 PMID:32442275

57. Xiong Y, Wei Y, Gu Y, Zhang S, Lyu J, Zhang B, Chen C, Zhu J, Wang $\mathrm{Y}$, Liu $\mathrm{H}$, Zhang $\mathrm{Y}$. DiseaseMeth version 2.0: a major expansion and update of the human disease methylation database. Nucleic Acids Res. 2017; 45:D888-95.

https://doi.org/10.1093/nar/gkw1123

PMID:27899673

58. Lv J, Liu H, Su J, Wu X, Liu H, Li B, Xiao X, Wang F, Wu Q, Zhang $Y$. DiseaseMeth: a human disease methylation database. Nucleic Acids Res. 2012; 40:D1030-5. https://doi.org/10.1093/nar/gkr1169 PMID:22135302

59. Dai S, Yan Y, Xu Z, Zeng S, Qian L, Huo L, Li X, Sun L, Gong Z. SCD1 Confers Temozolomide Resistance to Human Glioma Cells via the Akt/GSK3 $/ / \beta$-Catenin Signaling Axis. Front Pharmacol. 2018; 8:960. https://doi.org/10.3389/fphar.2017.00960 PMID:29354058 


\section{SUPPLEMENTARY MATERIALS}

\section{Supplementary Figures}

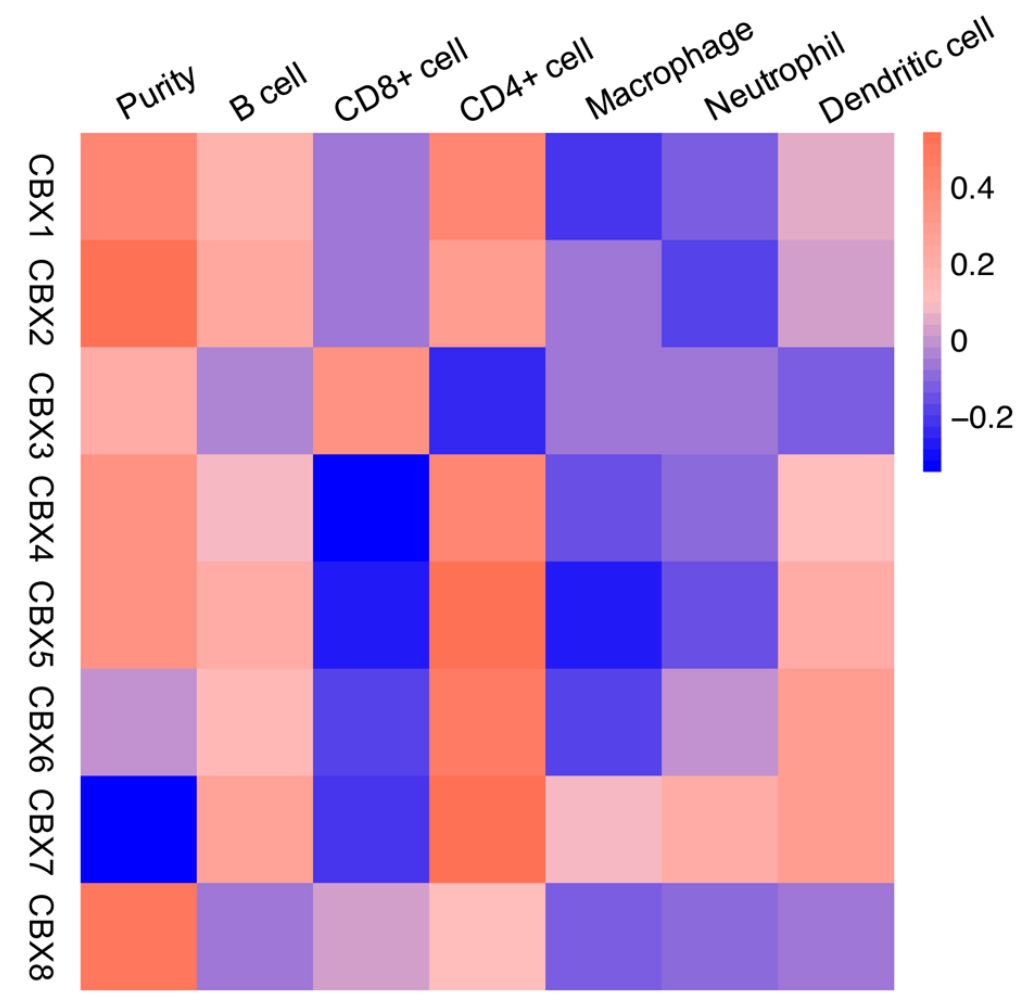

Supplementary Figure 1. The heat map showed the correlations between CBXs and immune cell infiltration. 
A

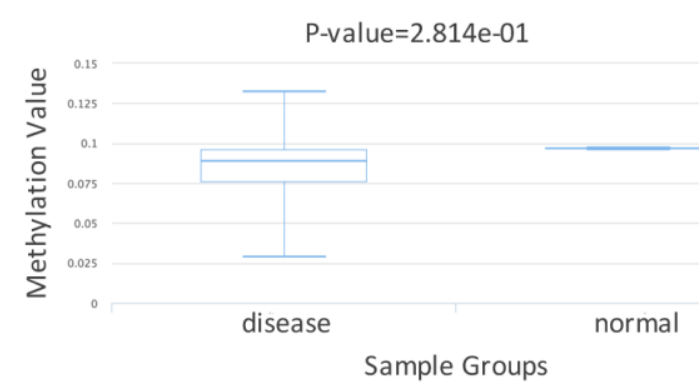

C

E

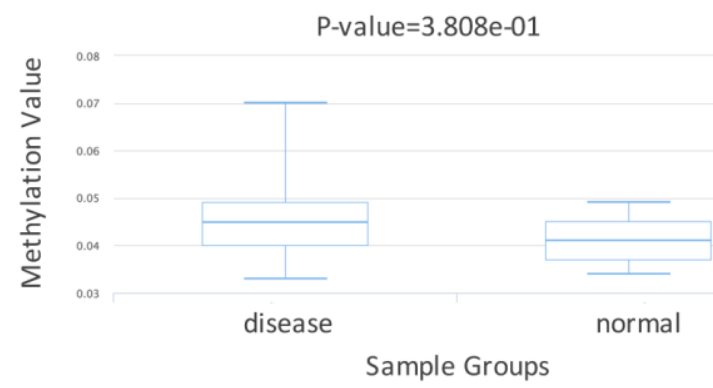

G

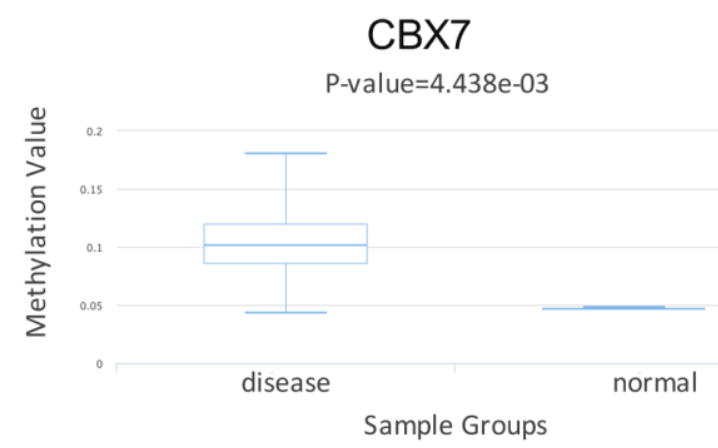

P-value $=7.920 \mathrm{e}-01$

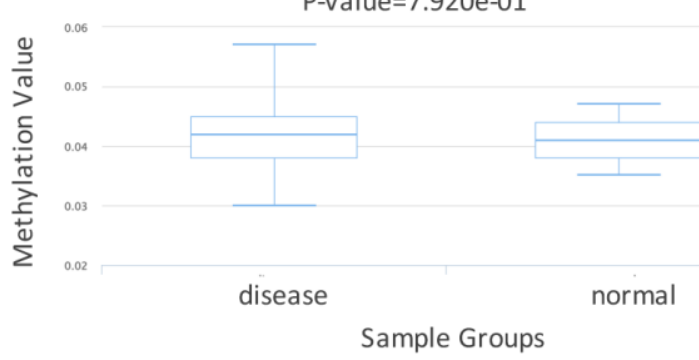

\section{CBX5}

B

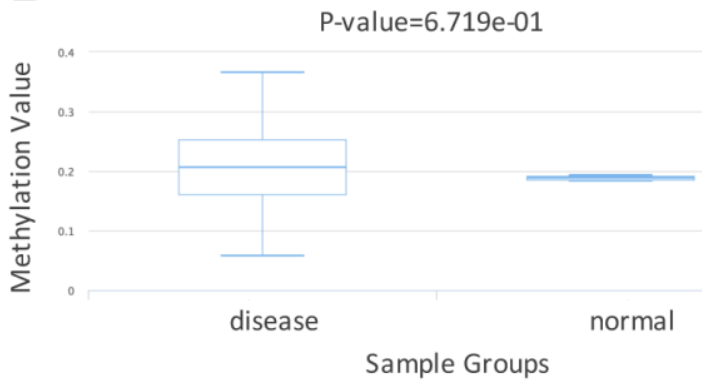

D

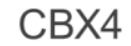

$\mathbf{F}$

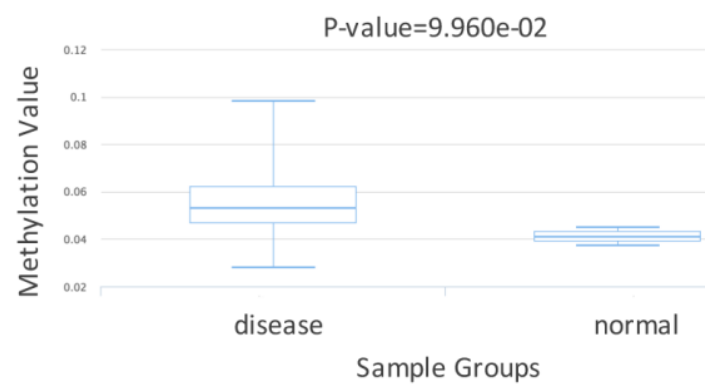

H

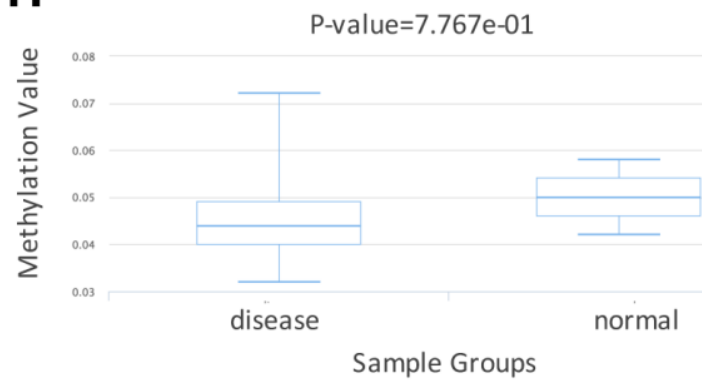

Supplementary Figure 2. DNA methylation levels of CBXs in GBM (DiseaseMeth). (A-H) The DNA methylation values of eight CBX members in GBM tissues and normal tissues. 


\section{Supplementary Tables}

Supplementary Table 1. A series of bioinformatics databases for analyzing the role of the CBX family in GBM.

\begin{tabular}{lccc}
\hline Databases & Authors & Samples & Homepage links \\
\hline GEPIA2 & Tang Z. et al. & Tissues & $\underline{\text { http://gepia2.cancer-pku.cn/ }}$ \\
UALCAN & Chandrashekar DS & Tissues & $\underline{\text { http://ualcan.path.uab.edu/index.html }}$ \\
The Human Protein Atlas & Anna Asplund. et al. & Tissues & $\underline{\text { https://www.proteinatlas.org/ }}$ \\
GlioVis & Bowman RL. et al. & Tissues & $\underline{\text { http://gliovis.bioinfo.cnio.es }}$ \\
cBioPortal & Cerami E. et al. & Tissues & $\underline{\text { http://www.cbioportal.org/ }}$ \\
Cytoscape & Doncheva NT et al. & - & - \\
WebGestalt & Liao Y. et al. & - & $\underline{\text { http://webgestalt.org/ }}$ \\
TIMER2.0 & Li T. et al. & Tissues & $\underline{\text { http://timer.cistrome.org/ }}$ \\
DiseaseMeth2.0 & Xiong Y. et al. & Tissues & $\underline{\text { http://bio-bigdata.hrbmu.edu.cn/diseasemeth/ }}$ \\
\hline
\end{tabular}


Supplementary Table 2. The CBX family associated co-expressed genes in GBM.

\begin{tabular}{|c|c|c|c|}
\hline Gene & Log ratio & p-Value & Expression \\
\hline NPNT & -1.28 & $9.99 \mathrm{E}-05$ & Unaltered group \\
\hline ADORA1 & -0.85 & $1.08 \mathrm{E}-04$ & Unaltered group \\
\hline ATP1B2 & -0.82 & $1.58 \mathrm{E}-04$ & Unaltered group \\
\hline EBF3 & 1.61 & $2.18 \mathrm{E}-04$ & Altered group \\
\hline BNC1 & 0.83 & $2.52 \mathrm{E}-04$ & Altered group \\
\hline MLC1 & -0.87 & $2.94 \mathrm{E}-04$ & Unaltered group \\
\hline PCDHGB7 & -1.62 & $2.95 \mathrm{E}-04$ & Unaltered group \\
\hline FGFR3 & -1.07 & 4.93E-04 & Unaltered group \\
\hline GRIK1 & -1.08 & 7.49E-04 & Unaltered group \\
\hline PLA2G5 & -1.36 & $7.85 \mathrm{E}-04$ & Unaltered group \\
\hline ESR2 & -0.86 & $8.00 \mathrm{E}-04$ & Unaltered group \\
\hline TMEM98 & 0.81 & $1.01 \mathrm{E}-03$ & Altered group \\
\hline $\mathrm{CDH} 4$ & -0.92 & $1.05 \mathrm{E}-03$ & Unaltered group \\
\hline SLC4A11 & -1 & $1.17 \mathrm{E}-03$ & Unaltered group \\
\hline DMRTA2 & -1.24 & $1.72 \mathrm{E}-03$ & Unaltered group \\
\hline CMYA5 & -0.83 & $2.13 \mathrm{E}-03$ & Unaltered group \\
\hline ARHGAP28 & 1 & $2.17 \mathrm{E}-03$ & Altered group \\
\hline FBLN7 & -0.82 & $2.20 \mathrm{E}-03$ & Unaltered group \\
\hline LRAT & -1.04 & $2.27 \mathrm{E}-03$ & Unaltered group \\
\hline EPCAM & 0.84 & $2.41 \mathrm{E}-03$ & Altered group \\
\hline GDPD2 & -0.83 & $2.41 \mathrm{E}-03$ & Unaltered group \\
\hline HOXB13 & 1.63 & $2.46 \mathrm{E}-03$ & Altered group \\
\hline ACSS3 & -0.86 & $2.95 \mathrm{E}-03$ & Unaltered group \\
\hline ALK & -0.89 & $3.04 \mathrm{E}-03$ & Unaltered group \\
\hline USP43 & 1.07 & $3.15 \mathrm{E}-03$ & Altered group \\
\hline PDE10A & 0.84 & $3.20 \mathrm{E}-03$ & Altered group \\
\hline ARSF & -1.09 & $3.38 \mathrm{E}-03$ & Unaltered group \\
\hline ADAMTS 17 & 0.83 & $3.41 \mathrm{E}-03$ & Altered group \\
\hline FAM181A & -0.81 & $3.68 \mathrm{E}-03$ & Unaltered group \\
\hline CNGA3 & -0.95 & $4.88 \mathrm{E}-03$ & Unaltered group \\
\hline TBX5 & 1.62 & $4.89 \mathrm{E}-03$ & Altered group \\
\hline DIRAS3 & -0.84 & $5.05 \mathrm{E}-03$ & Unaltered group \\
\hline LPAR4 & 0.92 & $5.14 \mathrm{E}-03$ & Altered group \\
\hline PTGER3 & 0.86 & $5.55 \mathrm{E}-03$ & Altered group \\
\hline DUSP9 & 0.84 & $5.62 \mathrm{E}-03$ & Altered group \\
\hline ARSI & -0.85 & $5.79 \mathrm{E}-03$ & Unaltered group \\
\hline TFCP2L1 & -0.91 & $5.83 \mathrm{E}-03$ & Unaltered group \\
\hline CLGN & 1.08 & $6.14 \mathrm{E}-03$ & Altered group \\
\hline DLX6 & 1.23 & $6.42 \mathrm{E}-03$ & Altered group \\
\hline GREB1L & 0.86 & $7.24 \mathrm{E}-03$ & Altered group \\
\hline PRAC2 & 1.12 & $7.42 \mathrm{E}-03$ & Altered group \\
\hline CRABP1 & 1.45 & 7.61E-03 & Altered group \\
\hline ATP13A4 & -0.82 & $7.87 \mathrm{E}-03$ & Unaltered group \\
\hline HOXD8 & 0.98 & $7.90 \mathrm{E}-03$ & Altered group \\
\hline HOXA11 & 0.95 & 8.04E-03 & Altered group \\
\hline WNT7A & -0.9 & $8.24 \mathrm{E}-03$ & Unaltered group \\
\hline CHRNA3 & 0.87 & $8.25 \mathrm{E}-03$ & Altered group \\
\hline NXPH2 & 0.93 & $8.28 \mathrm{E}-03$ & Altered group \\
\hline ELAVL2 & 1.03 & $8.95 \mathrm{E}-03$ & Altered group \\
\hline NKX2-5 & -1.09 & $9.57 \mathrm{E}-03$ & Unaltered group \\
\hline NNAT & 1.35 & $9.88 \mathrm{E}-03$ & Altered group \\
\hline HS3ST3B1 & -0.84 & 0.01 & Unaltered group \\
\hline HOXC6 & 0.86 & 0.0102 & Altered group \\
\hline
\end{tabular}




\begin{tabular}{|c|c|c|c|}
\hline ELOVL2 & -0.83 & 0.0111 & Unaltered group \\
\hline SAMD11 & 0.85 & 0.0112 & Altered group \\
\hline ECEL1 & 1.12 & 0.0117 & Altered group \\
\hline SLC1A6 & 1.11 & 0.0122 & Altered group \\
\hline FEV & 0.93 & 0.0127 & Altered group \\
\hline CYP27C1 & 0.9 & 0.0129 & Altered group \\
\hline DMRT2 & 0.92 & 0.0131 & Altered group \\
\hline PAK5 & 1.11 & 0.0131 & Altered group \\
\hline GRIA1 & -0.85 & 0.0136 & Unaltered group \\
\hline TMEM229A & -0.85 & 0.0137 & Unaltered group \\
\hline ALDH1A3 & 1.14 & 0.0138 & Altered group \\
\hline DBX2 & -0.81 & 0.014 & Unaltered group \\
\hline CHRDL2 & -0.97 & 0.0156 & Unaltered group \\
\hline C6ORF15 & -1.23 & 0.0162 & Unaltered group \\
\hline MNX1 & 1 & 0.0172 & Altered group \\
\hline TLX1 & 1.09 & 0.0176 & Altered group \\
\hline LHX1 & 0.85 & 0.0178 & Altered group \\
\hline OTX1 & -0.86 & 0.018 & Unaltered group \\
\hline CPNE4 & -1.13 & 0.018 & Unaltered group \\
\hline CAMKV & 0.9 & 0.0184 & Altered group \\
\hline DCT & 0.82 & 0.0186 & Altered group \\
\hline HOXA13 & 0.87 & 0.0187 & Altered group \\
\hline HOPX & -0.85 & 0.0187 & Unaltered group \\
\hline BARX1 & 0.87 & 0.0202 & Altered group \\
\hline VIPR2 & 1.19 & 0.0203 & Altered group \\
\hline BHLHE22 & 0.91 & 0.0207 & Altered group \\
\hline DYDC2 & 0.83 & 0.0208 & Altered group \\
\hline SHISA2 & 0.87 & 0.0223 & Altered group \\
\hline HOXC13 & 1.14 & 0.0227 & Altered group \\
\hline MOXD1 & -0.86 & 0.023 & Unaltered group \\
\hline IGF2BP1 & 0.83 & 0.0239 & Altered group \\
\hline HMX1 & 1.2 & 0.0247 & Altered group \\
\hline SFRP5 & 0.92 & 0.0251 & Altered group \\
\hline CDR1 & 0.91 & 0.0276 & Altered group \\
\hline APCDD1L & -0.89 & 0.0285 & Unaltered group \\
\hline SLC44A5 & 0.91 & 0.0287 & Altered group \\
\hline ABCA13 & -0.81 & 0.0293 & Unaltered group \\
\hline IRX1 & 1.38 & 0.0301 & Altered group \\
\hline GABRB3 & 0.88 & 0.0303 & Altered group \\
\hline NPPA & 0.93 & 0.0314 & Altered group \\
\hline PLPPR3 & 0.98 & 0.0321 & Altered group \\
\hline HOXC9 & 0.86 & 0.0325 & Altered group \\
\hline CNPY1 & 0.84 & 0.0345 & Altered group \\
\hline KLRC4 & 0.83 & 0.035 & Altered group \\
\hline NPY2R & -0.9 & 0.0383 & Unaltered group \\
\hline HOXC11 & 0.94 & 0.0384 & Altered group \\
\hline JCHAIN & 0.99 & 0.04 & Altered group \\
\hline $\mathrm{HOXC10}$ & 1 & 0.0408 & Altered group \\
\hline CXCL14 & -0.83 & 0.0414 & Unaltered group \\
\hline GABRA3 & 0.81 & 0.0468 & Altered group \\
\hline PCDHGA10 & -0.91 & 0.049 & Unaltered group \\
\hline
\end{tabular}

